\title{
Host CYP27A1 expression is essential for ovarian cancer progression
}

\author{
Sisi He1, Liqian Ma1, Amy E Baek¹, Anna Vardanyan1, Varsha Vembar¹, Joy J Chen', Adam T Nelson¹, \\ Joanna E Burdette 2,5 and Erik R Nelson $1,3,4,5,6$ \\ 1Department of Molecular and Integrative Physiology, University of Illinois at Urbana Champaign, Urbana, Illinois, USA \\ 2Department of Medicinal Chemistry and Pharmacognosy, University of Illinois at Chicago, Chicago, Illinois, USA \\ ${ }^{3}$ Cancer Center at Illinois, University of Illinois at Urbana Champaign, Urbana, Illinois, USA \\ ${ }^{4}$ Division of Nutritional Sciences, University of Illinois at Urbana Champaign, Urbana, Illinois, USA \\ 5University of Illinois Cancer Center, University of Illinois at Chicago, Chicago, Illinois, USA \\ ${ }^{6}$ Carl R. Woese Institute for Genomic Biology, Anticancer Discovery from Pets to People Theme, University of Illinois at Urbana Champaign, \\ Urbana, Illinois, USA
}

Correspondence should be addressed to E R Nelson: enels@illinois.edu

\begin{abstract}
There is an urgent need for more effective strategies to treat ovarian cancer. Elevated cholesterol levels are associated with a decreased progression-free survival time (PFS) while statins are protective. 27-Hydroxycholesterol $(27 \mathrm{HC})$, a primary metabolite of cholesterol, has been shown to modulate the activities of the estrogen receptors (ERs) and liver $x$ receptors (LXRs) providing a potential mechanistic link between cholesterol and ovarian cancer progression. We found that high expression of CYP27A1, the enzyme responsible for the synthesis of $27 \mathrm{HC}$, was associated with decreased PFS, while high expression of CYP7B1, responsible for $27 \mathrm{HC}$ catabolism, was associated with increased PFS. However, $27 \mathrm{HC}$ decreased the cellular proliferation of various ovarian cancer cell lines in an LXR-dependent manner. Intriguingly, ID8 grafts were unable to effectively establish in CYP27A1-I- mice, indicating involvement of the host environment. Tumors from mice treated with $27 \mathrm{HC}$ had altered myeloid cell composition, and cells from the marrow stem cell lineage were found to be responsible for the effects in CYP27A1-I- mice. While inhibition of CYP27A1 or immune checkpoint did not significantly alter tumor size, their combination did, thereby highlighting this axis as a therapeutic target.
\end{abstract}

\author{
Key Words \\ - cholesterol \\ - ovarian cancer \\ - 27-hydroxycholesterol \\ - tumor microenvironment \\ - myeloid-derived suppressor \\ cells
}

Endocrine-Related Cancer (2019) 26, 659-675

\section{Introduction}

It is expected that there will be approximately 22,530 new cases of ovarian cancer diagnosed in the USA in 2019 , accounting for roughly $2.5 \%$ of all female cancers (American Cancer Society 2019). Current therapeutic standard of care includes debulking surgery followed by cycles of chemotherapy, typically paclitaxel combined with carboplatin. Unfortunately however, ovarian cancer continues to have an expected 5-year overall survival rate of less than $50 \%$, accounting for it being responsible for 5\% of all cancer-related deaths in women (American Cancer Society 2019). Poor survival has been attributed to the fact that most women present with advanced stages of the disease, and both de novo and acquired resistance to existing chemotherapy regimens. Therefore, there is a sense of urgency to develop novel diagnostic and therapeutic approaches for this disease.

The majority of ovarian cancers are of epithelial origin, although approximately $2 \%$ of cases are germ
(C) 2019 Society for Endocrinology Published by Bioscientifica Ltd. Printed in Great Britain 
cell and 1\% are stromal (sex-chord) (American Cancer Society 2019). Epithelial cancers are further subdivided into serous, endometrioid, mucinous and clear cell types, with serous accounting for the majority $(\sim 52 \%)$. Of the serous tumors, the majority present as high-grade serous carcinomas. Although the ovary itself was considered as the origin of ovarian cancer (Meyn \& Lim 2017), recent evidence suggests that the fallopian tube (oviduct) is likely the origin for the majority of high-grade serous epithelial cancers that subsequently spread to the ovaries (Eckert et al. 2016, Labidi-Galy et al. 2017).

Although hereditary causes such as mutations in BRCA1 or 2 play important causal roles, they only account for $20 \%$ of cases (Norquist et al. 2016), with the majority of ovarian cancer cases appearing to be spontaneous. Highgrade serous ovarian adenocarcinomas have been found to predominantly harbor mutations of TP53, with other common mutations found within NF1, BRCA1, BRCA2, RB1 and CDK12, although at a much lower prevalence (Cancer Genome Atlas Research Network et al. 2011). Gene breakage events often lead to common inactivation of RB1, NF1, RAD51 and PTEN (Patch et al. 2015). Other common genomic alterations include reversions of BRCA1 or 2 mutations, loss of BRCA1 promoter methylation, promoter fusion associated with increased MDR expression (a multi-drug efflux pump), and altered miRNA expression, etc (Cancer Genome Atlas Research Network et al. 2011, Patch et al. 2015). Furthermore, enrichment of various $\mathrm{T}$ cell populations has been found to be associated with a positive prognosis (Yang et al. 2018). It is of significance, therefore, that obesity has been associated with an increased risk of ovarian cancer among women who have not taken hormone replacement therapy (Collaborative Group on Epidemiological Studies of Ovarian Cancer 2012).

Furthermore, among ovarian cancer patients, obesity is associated with both decreased progressionfree and disease-specific survival (PFS and DSS) (Nagle et al. 2015). While the associations between obesity and ovarian cancer are likely complex and multifactorial, it is significant that elevated circulating cholesterol is often observed in obese patients (Must et al. 1999, Gostynski et al. 2004, Centers for Disease Control and Prevention 2010), and a strong association exists between elevated plasma LDL cholesterol and decreased PFS and DSS (Li et al. 2010). Conversely, patients taking cholesterollowering drugs (inhibitors of HMGCoA-reductase; statins) have been found to have significantly increased PFS and DSS (Elmore et al. 2008, Lavie et al. 2013, Habis et al. 2014, Akinwunmi et al. 2019). Collectively, these data indicate that cholesterol likely plays an important role in the pathophysiology of ovarian cancer and that cholesterol may be one contributing factor to the associations with obesity and worse prognosis.

Cholesterol is primarily metabolized in the liver by the enzyme CYP7A1 in the traditional bile acid synthesis pathway. However, it can also be metabolized by CYP27A1 in the acidic bile acid pathway, into 27-hydroxycholesterol (27HC). Intriguingly, several studies have defined 27HC as a ligand for both the estrogen receptors (ERs) and liver X receptors (LXRs) (Umetani et al. 2007, DuSell et al. 2008, Centers for Disease Control and Prevention 2010, Nelson et al. 2011, 2013), providing a potential mechanism for the actions of cholesterol. As a primary metabolite of cholesterol, 27HC is the most abundant oxysterol in circulation, and its plasma levels are closely associated with those of cholesterol (Karuna et al. 2011). Indeed, previous studies have found that $27 \mathrm{HC}$ promotes breast tumor growth by functioning as an ER agonist to induce cellular proliferation (Nelson et al. 2013, Wu et al. 2013). However, a role for $27 \mathrm{HC}$ in ovarian cancer remains undetermined. Furthermore, unlike in breast cancer, the involvement of the ERs in the pathophysiology of ovarian cancer are not clear. Anti-estrogens appear to only be advantageous in the ovarian endometrioid carcinomas and not in the more common high-grade serous carcinomas (Lindemann et al. 2017). Therefore, we initiated a series of studies to define the potential roles of $27 \mathrm{HC}$ in the progression of ovarian cancer .

\section{Materials and methods}

\section{Survival analysis}

Kaplan-Meier plots were graphed using Graphpad Prism 6 with data and statistical analysis from Kaplan-Meier plotter [Ovarian Cancer] (http://kmplot.com/analysis/ index.php?p=service\&cancer=ovar), an online tool for genome-wide validation of survival-associated biomarkers (Gyorffy et al. 2010, 2012).

Forest plots were generated using R 3.5.0 (https:// www.r-project.org/) using the curated OvarianData package (Haibe-Kains et al. 2012, Ganzfried et al. 2013). Databases and patients with relevant survival information (OS or PFS) were selected and gene expressions were rescaled to z-score for analysis. survival and metafor packages were used to calculate hazard ratios and generate forest plots. $\mathrm{R}$ script available upon request. 
Data containing progression-free survival and tumoral CYP27A1 or CYP7B1 expression were extracted from the Kaplan-Meier Plotter with auto select best cutoff and follow up threshold of 5 years. A total of 1435 ovarian cancer patients were available, and they were split in two cohorts: high and low expression. Progression-free survival curves were plotted, and significance was calculated using either the Mantel-Cox or Gehan-Breslow-Wilcoxon test.

\section{Reagents}

HCD (high cholesterol diet, 2\% cholesterol and 0.5\% sodium cholate) and CD (control diet, 0.5\% sodium cholate) were purchased from TestDiet (5CNY and 5BRW). 27HC and GW273297X were synthesized by Sai Life (Hyderabad, India). GSK 2033 (cat\#1221277-90-2), sulfamethoxazole (cat\#723-46-6) and trimethoprim (cat\#738-70-5) were purchased from Sigma-Aldrich. ICI 182,780 was synthesized by Small Molecule Incorporated (Beijing, China). LDL cholesterol was purchased from Lee Biosolutions (lot\#W21129, cat\#360-10). 17 $\beta$-Estradiol (cat\#101656) and carboplatin (lot\#M9733, cat\#198873) were obtained from MP Biomedicals. Anti-PD-L1 (clone 10F.962, lot\#615416D1, cat\#BE0115) and IgG2b isotype control (Clone LTF-2, cat\#BE0090) were purchased from BioXCell. Flow cytometry antibodies were from BD Pharmingen: CD11b (Cat \#557686), Ly6C (Cat \#553104), Ly6G (Cat \#551461), CD3 (Cat \#555275), CD4 (Cat \#553729), CD8 (Cat \#557682), CD44 (Cat\#553134), CD69 (Cat\#557392). Recombinant mouse GM-CSF (Cat \#P01587) and ID6 (Cat \#P08505) were purchased from Novoprotein.

\section{Cell culture}

All cell lines used were obtained and maintained at 37C and 5\% CO2. HeyA8 were a gift from Dr S Gaillard (Duke University, now at John Hopkins) and were cultured in RPMI supplemented with 10\% fetal bovine serum (FBS). ES2, PEO4, CaOV3 and IGROV were a gift from David J Shapiro (University of Illinois Urbana-Champaign). ES2 were cultured in McCoy's 5a supplemented with 10\% FBS. PEO4 and CaOV3 were cultured in DMEM supplemented with 10\% FBS. IRGOV and OVCAR3 were cultured in RPMI 1640 with 10-20\% FBS. ID8-luc were given by Dr Robin Bachelder (Duke University Medical School) and were cultured in DMEM with 4\% FBS. Transformed murine oviductal epithelial (MOE) cells were developed by Dr Joanna E Burdette (University of Illinois at Chicago) and were initially cultured in MTEC with L-glutamine, $10 \%$ FBS, insulin, EGF and estradiol, and then only in MTEC with L-glutamine and 10\% FBS (Eddie et al. 2015).

\section{Animal models}

All animal experiments and procedures were approved by the Institutional Animal Care and Use Committee (IACUC) at University of Illinois. C57BL/6 WT and FVB/NJ mice were obtained from Charles River or Jackson Laboratories. CYP27A1-1- mice were bred in house. Animals were randomized into indicated treatment groups prior to tumor engraftment.

For tumor establishment, cancer cells (suspended in $15 \mu \mathrm{L}$ media) were mixed with $10 \mu \mathrm{L}$ matrigel (Fisher, Cat\#CB-40234) and orthotopically grafted into the ovary/bursa of one ovary. For the ID8-luc model, $1 \times 10^{6}$ cells/mice were orthotopically grafted in C57BL/6 WT or CYP27A1-/- mice. Tumor growth was monitored over time with in vivo bioluminescence imaging (IVIS). Final primary tumor weight and peritoneal colonization were measured at necropsy. For the MOE model, $0.25 \times 10^{6}$ cells/mice were orthotopically grafted in FVB/NJ mice. Tumor burden was assessed and measured upon necropsy. Number of colonized nodules were obtained by counting metastatic nodules on the intestinal epithelium. Peritoneal spread was measured by weighing metastatic nodules extracted from the abdominal cavity and peritoneal cavity. For intraperitoneal graft (ip) (Fig. 5G), 107 ID8-luc cells were injected into the intraperitoneal space. Tumor growth was monitored over time with in vivo bioluminescence imaging (IVIS) and tumor burden was assessed upon necropsy.

\section{Dietary elevation of cholesterol}

Mice were placed on HCD or CD 4 weeks before tumor engraftment and maintained throughout.

\section{Proliferation assay}

An optimized number of cells for each cell line was plated in 96-well plate. After $24 \mathrm{~h}$, treatment solutions were prepared by dilution of stock with culture media. Cell concentration at different time points were measured based on DNA content (Hoescht 33342 staining) as previously described (Nelson et al. 2013).

\section{In vivo treatments}

For in vivo treatments, drugs were solubilized in corresponding vehicles and subsequently sterile filtered using $0.2 \mu \mathrm{m}$ filter. $27 \mathrm{HC}$ was solubilized in $40 \%$ 2-hydroxypropyl- $\beta$-cyclodextrin and administrated via daily subcutaneous injection $(20 \mathrm{mg} / \mathrm{kg})$. Carboplatin was 
solubilized in PBS or 5\% dextrose and administrated via intraperitoneal (IP) injection. For the early stage tumor study, carboplatin was dosed at $16 \mathrm{mg} / \mathrm{kg}$ (in PBS), on days $7,12,16,20$ and 24 . For the advanced stage tumor study, carboplatin was injected at $40 \mathrm{mg} / \mathrm{kg}$ (in $5 \%$ dextrose) every 4 days. CYP27A1 inhibitor (GW273297X) was dissolved in 10\% ethanol and 90\% corn oil and administrated via daily IP injection $(100 \mathrm{mg} / \mathrm{kg})$. Anti-PD-L1 or IgG2b control were diluted to $200 \mu \mathrm{g} / \mathrm{mice}$ with PBS and administered every 2 days via IP injection.

\section{Bone marrow transplant}

Recipient CYP27A1-l- mice that were between 8 and 10 months old were selected and randomized. A week before irradiation, recipient mice were provided with water and wet food containing sulfamethoxazol $(200 \mathrm{mg} / 5 \mathrm{~mL})$ and trimethoprim $(40 \mathrm{mg} / 5 \mathrm{~mL})$ and acidified with hydrochloric acid to $\mathrm{pH}$ 2.4-3.1. Medicated water and wet food were provided to animals up to 3 weeks following the irradiation and bone marrow transplant procedures, and mice were kept on acidified water for 2 months. For irradiation, recipient mice received $12 \mathrm{~Gy}$ of radiation $(2 \times 6 \mathrm{~Gy}$, approximately $4 \mathrm{~h}$ apart) from a Colbalt 60 source. Donor WT and CYP27A1-/- mice were euthanized, and their bone marrow cells were extracted via fast extraction method (Amend et al. 2016). After the second irradiation session, each irradiated recipient mouse received $1 \times 10^{8}$ bone marrow cells obtained from donor mice, via retroorbital injection. 29 days after bone marrow transplant, ID8-luc cells were grafted into ovary/bursa area of mice.

\section{Flow cytometry}

Primary tumors were extracted and digested in collagenase A solution. Spleen and lymph nodes were extracted and mechanically dissociated. Bone marrow cells were obtained via, traditional flushing or the fast extraction method (Amend et al. 2016). Resulting slurry were filtered through $70 \mu \mathrm{m}$ filter and red blood cells were lysed with ACK buffer. Lymph nodes were not subjected to ACK buffer treatment. Dispensed cells were stained with antibodies (1:100 dilution) and analyzed by flow cytometry. Specific antibodies and staining strategies are detailed previously (Yu et al. 2016, Baek et al. 2017).

\section{MDSC in vitro differentiation assay}

Bone marrow cells were harvested from mouse tibias and femurs under sterile conditions. After red blood cell lysis with ACK buffer, $2.5 \times 10^{6}$ cells were plated and cultured in $10 \mathrm{~mL}$ of $\mathrm{RPMI}+10 \%$ FBS with $40 \mathrm{ng} / \mathrm{mL}$ mouse recombinant GM-CSF $(40 \mathrm{ng} / \mathrm{mL})$ and IL-6 $(40 \mathrm{ng} / \mathrm{mL})$ for 6 days. Vehicle or $27 \mathrm{HC}$ treatments were added to culture media. For 6-day cultures, cytokines and Veh/27HC treatments were refreshed on day 3. Following incubation, floating and adherent cells were collected and stained for flow analysis.

\section{Gene expression}

RNA was extracted with GeneJet RNA Purification kit (cat\#K0731, Thermo Fisher) and reverse-transcribed into cDNA library with iScript Reverse Transcription Supermix (cat\#1708841BUN, Biorad). qPCR Primers were designed via Primer-BLAST (https://www.ncbi.nlm.nih.gov/tools/ primer-blast/) or PrimerBot (http://primerbot.duhs. duke.edu/). mRNA expression was investigated with RT-qPCR using iTaq Universal SYBR Green Supermix (cat\#1725125, Biorad).

\section{TCGA analysis of CYP27A1 and CD33}

Provisional TCGA data from the accessed from c-bioportal in April of 2018. Data from patients whose gene expression for either CYP27A1 or CD33 were ' $\mathrm{NaN}^{\prime}$ ' were removed from further analysis, leaving data from 551 patients. Array gene expression was transformed (2 expression) and parsed into high and low groups, based on median CYP27A1 expression. CD33 expression was plotted based on high or low CYP27A1 expression, and significance was tested by a two-tailed $T$ test.

\section{Statistics}

Data are presented as mean \pm standard error of the mean, assessed for normal distribution and natural $\log$ transformed as necessary prior to statistical tests. Supplementary Figure 1 (see section on supplementary data given at the end of this article): Linear regression analysis was performed, and differences in slope was determined by ANOVA. Two-tailed $T$ tests were used to compare two groups (Fig. 2A, B, C, Fig. 5C, F, G, Fig. 6, Supplementary Fig. 4C and Supplementary Fig. 6). For multiple comparisons with a single variable (Fig. 3, Fig. 4 and Supplementary Fig. 3), one-way ANOVA followed by the Student-Newman-Keuls multiple comparison test was used. For multiple comparisons with two variables (Fig. 2D, E, F, Fig. 5A, B, Fig. 7A and Supplementary Fig. 5B), twoway ANOVA followed by a Bonferroni multiple comparison (c) 2019 Society for Endocrinology Published by Bioscientifica Ltd. Printed in Great Britain 
test was used. For proportion testing (Fig. 7B, Fig. 8 and Supplementary Fig. 5C), a chi-square and Fisher's exact test was used. Statistical significance was determined as $P<0.05$, and indicated with either an asterisk or different letters.

\section{Results}

\section{Dietary cholesterol modestly promotes ovarian tumor growth}

Retrospective data indicate that circulating LDLcholesterol is associated with a poor prognosis (Li et al. 2010), while patients on statins experience an increased progression-free survival time (Elmore et al. 2008, Lavie et al. 2013, Habis et al. 2014, Akinwunmi et al. 2019). Therefore, we first directly tested the impact of elevated dietary cholesterol on ovarian tumor growth. Mice were placed on either a control diet $(\mathrm{CD}$, consisting of $0.5 \%$ sodium cholate) or a high cholesterol diet (HCD, $2 \%$ cholesterol, $0.5 \%$ sodium cholate) for 4 weeks prior to graft and throughout the study. ID8 cells expressing luciferase were grafted directly into one ovarian bursal region of the mice. Resulting tumor burden was assessed by bioluminescent imaging. It is important to note that the HCD was iso-caloric to the $\mathrm{CD}$, and mice on an HCD did not gain weight to the same extent as mice on a $\mathrm{CD}$, and in fact, lost weight as the study progressed (Supplementary Fig. 1A). However, the growth rate of total tumor burden was modestly increased in mice on an HCD (Supplementary Fig. 1B), thereby providing direct support for the clinical observations implicating cholesterol in the progression of ovarian cancer.

\section{HC metabolism is associated with ovarian cancer prognosis}

Given our results indicating that cholesterol increases ovarian tumor growth, it was of interest that the primary metabolite of cholesterol 27HC has been found to actively engage both the ERs and LXRs and that 27HC has been shown to promote breast cancer progression (Nelson et al. 2013, Wu et al. 2013, Baek et al. 2017). Therefore, we speculated that this oxysterol may also play an important pathophysiological role in ovarian cancer. It was therefore noteworthy that among patients with optimal debulking surgery, high tumoral mRNA expression of CYP27A1, the enzyme responsible for the synthesis of $27 \mathrm{HC}$ from cholesterol, is associated with a significant decrease in overall survival
(OS) when patients presented at an early stage (stages 1 and 2), while it was associated with increased OS when patients presented with later stage disease (stages 3 and 4) (Fig. 1A and B). However, high CYP27A1 expression was a poor prognostic marker for PFS, when comparing patients to the lower quartile of expression (shift in median PFS by more than 9 months, Fig. 1C), as evaluated by Kaplan-Meier Plotter (Gyorffy et al. 2012).

These analyses include all samples available, which is heavily weighted towards the most frequent ovarian cancer subtype, high-grade serous. Indeed, the same trends were observed when we restricted our analyses to the serous subtype (Supplementary Fig. 2A and B). Due to the limited sample number, analysis of low-grade serous tumors was underpowered to draw firm conclusions. Curiously, when considered as a continuous variable across several publicly available datasets, CYP27A1 is not associated with either OS or PFS, indicating that there may be a certain threshold in terms of CYP27A1 expression and risk of recurrence (Supplementary Fig. 1C and D). Conversely, high expression of CYP7B1, the enzyme responsible for $27 \mathrm{HC}$ catabolism, is associated with an increased PFS (increase in median PFS of 3 months), but not in overall survival (Fig. 2D, E and F). When considered as a continuous variable, across several datasets, CYP7B1 expression was associated with a decreased overall survival (Supplementary Fig. 2E).

Interestingly, when considered as a continuous variable, the expression of the receptors for 27HC (ER $\alpha$ and $\operatorname{LXR} \alpha$ ) are associated with a good overall survival (Supplementary Fig. 2). Likewise, the expression of a known ER target gene, TFF1, was also associated with a better PFS (Supplementary Fig. 2). However, ABCA1, a known LXR target gene, was associated with a worse PFS (Supplementary Fig. 2). Overall, these data implicate $27 \mathrm{HC}$ in the pathophysiology of ovarian cancer, although they also indicate nuanced biology in terms of cholesterol homeostasis and cancer progression. It is important to note that due to the limits of publicly available data, our analyses have not controlled for covariates such as tumor grade, body mass index, circulating cholesterol levels, use of statins or age. All of these would be expected to impact ovarian cancer progression and may interact with the 27HC axis. When assessed independently, tumor grade and age were associated with decreased OS. However, age was not a prognostic of PFS (Supplementary Fig. 2G, H and I). Since CYP27A1 was associated with decreased PFS, it would suggest that this is independent of age. However, at this time, the data available would be underpowered to parse by quartile and control for age. 

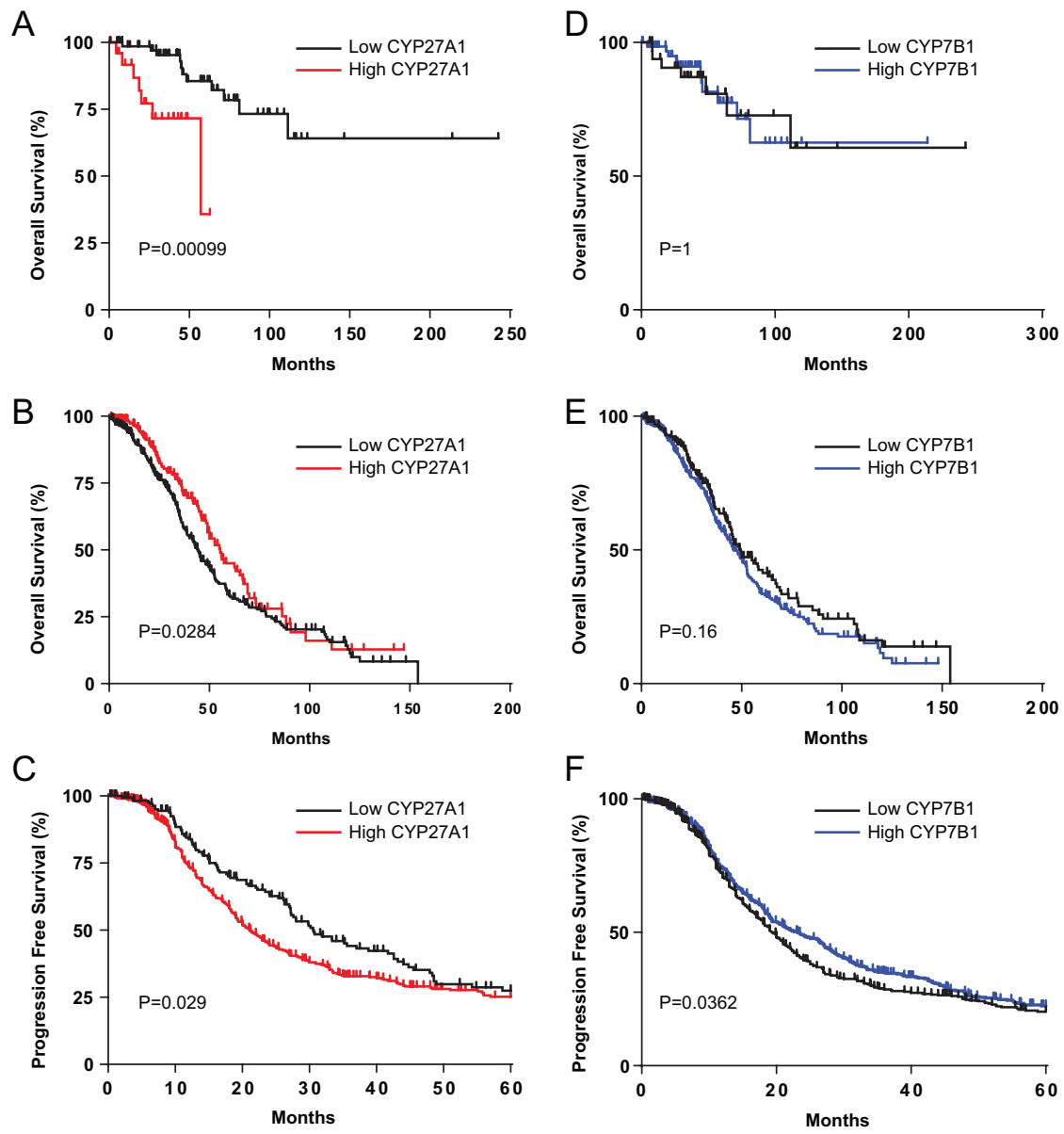

\section{Figure 1}

Enzymes responsible for $27 \mathrm{HC}$ synthesis and catabolism are implicated in overall and progression free survival of ovarian cancer patients. Data and statistical analysis were obtained with Kaplan-Meier Plotter, an online tool for genome-wide validation of survival-associated biomarkers, which curated TCGA, GEO and EGA databases. Among ovarian cancer patients with optimal debulking: (A) Elevated expression of CYP27A1 (upper quartile), the enzyme responsible for $27 \mathrm{HC}$ synthesis, is associated with poor overall survival among patients diagnosed with early stage disease (stages 1 and 2) $(n=102)$. (B) Elevated expression of CYP27A1 (upper tertile) within patients diagnosed with advanced stage disease (stages 3 and 4$)$ is slightly protective $(n=595)$. (C) Very low CYP27A1 expression (lower quartile) is protective against cancer recurrence $(n=696)$. (D and E) Elevated expression of CYP7B1 (lower tertile), the enzyme responsible for $27 \mathrm{HC}$ catabolism is not associated with overall survival among patients diagnosed with either (D) early stage disease (stages 1 and 2,n=102) or (E) advanced stage disease (stages 3 and 4, $n=595$ ). (F) Among all ovarian cancer patients, elevated expression of CYP7B1 (upper 57\%) is associated with an increased progression-free survival time. For this analysis (F) the auto-calculated best cutoff was selected with follow up threshold of 5 years $(n=1435)$. P values as determined by the Mantel-Cox or Gehan-Breslow-Wilcoxon test are as indicated in the figure.

\section{HC impairs ovarian cancer cellular proliferation; the apparent $27 \mathrm{HC}$ paradox}

Oxysterols such as $27 \mathrm{HC}$ are well-known agonists of the LXRs, which engage machinery involved in cholesterol homeostasis resulting in cholesterol efflux, inhibition of cholesterol synthesis and decreased uptake (Szanto et al. 2004). These effects are not conducive to the cholesterol demand of rapidly proliferating cells and as such, it would be expected that they would have a growth-inhibitory effect on cancer cells. Indeed, synthetic LXR agonists have been found to inhibit proliferation of several cancer models including ovarian, breast, prostate and metastatic melanoma (Lee et al. 2008, Vedin et al. 2009, Pommier et al. 2010, Scoles et al. 2010, Nelson et al. 2013, Nguyen-Vu et al. 2013, Pencheva et al. 2014). In breast cancer, we found that 27HC-stimulated tumor growth due to its actions on the ER, which could override the effects of LXR activation (Nelson et al. 2013). Although the majority of ovarian cancer cases exhibit ER positive staining, the most common subtype (high-grade serous) tends not to respond to anti-estrogen therapy (tamoxifen
C 2019 Society for Endocrinology Published by Bioscientifica Ltd. Printed in Great Britain 


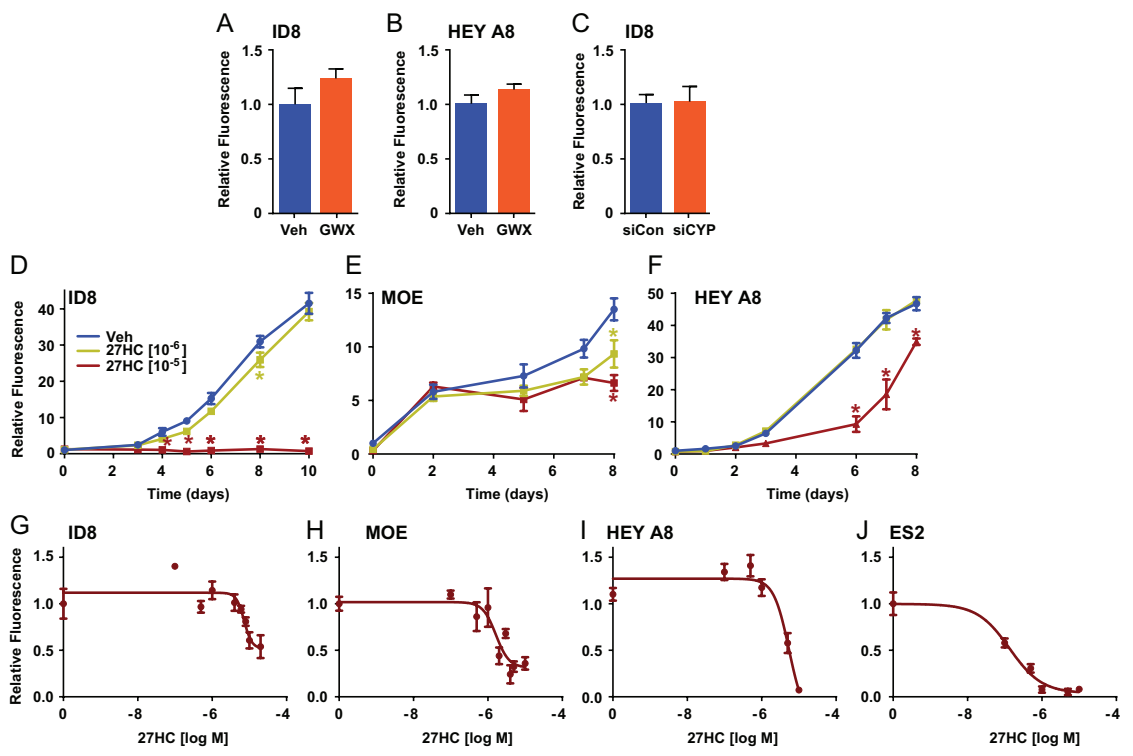

\section{Figure 2}

$27 \mathrm{HC}$ displays anti-proliferative activity in ovarian cancer cells. (A and B) Inhibition of CYP27A1 with the small-molecule inhibitor GW273297X (GWX, $10 \mu \mathrm{M})$ does not significantly alter the proliferation of ID8 or HEY A8 ovarian cancer cells in vitro. Cells were treated for 6 days with either vehicle or GWX prior to assessment of total DNA by Hoescht 33342 staining. (C) siRNA-mediated knockdown of CYP27A1 does not significantly alter the proliferation of ID8 cells in vitro. (D, E and F) Treatment with exogenous $27 \mathrm{HC}$ at indicated doses significantly decreases proliferation of ID8, MOE or HEY A8 cells in vitro. ( $G, H, I$ and J) Doseresponse curves of $27 \mathrm{HC}$ at indicated doses on inhibition of ID8, MOE, HEY A8 or ES2 proliferation. Non-linear regression was used to fit the curve. Statistics for: A-C unpaired T test. D-F two-way ANOVA followed by Bonferroni $T$ test, asterisks indicating significant differences from vehicle $(P<0.05)$. or aromatase inhibition), nor is ER staining prognostic of outcome in these patients, indicating that the growth of these tumors is not dependent on ER signaling (Hogdall et al. 2007, Voutsadakis 2016). Thus, it was not outwardly clear how 27HC would impact the cellular proliferation of ovarian cancer.

A summary of the expression of key genes within the cell models used in these studies can be found in Supplementary Table 1 . We first evaluated the effect of inhibiting CYP27A1 on the proliferation of murine ID8 and human HEY A8 cells. As depicted in Fig. 2A and B, no significant changes in proliferation were observed upon treatment with the small-molecule inhibitor of CYP27A1, GW273297X. Previous studies have found that GW273297X effectively reduces 27HC levels both in vitro and in vivo (Lyons \& Brown 2001, Nelson et al. 2013, Baek et al. 2017). In ID8 cells, siRNA resulted in $>60 \%$ knockdown of CYP27A1 mRNA $24 \mathrm{~h}$ post transfection and $>50 \%$ knockdown by the end of the proliferation assay (8 days post transfection, data not shown). Similar to inhibition with a small molecule, ID8 proliferation was not significantly altered upon siRNA knockdown of CYP27A1 (Fig. 2C). The lack of impact on proliferation when CYP27A1 was either inhibited or knocked down may indicate that the expression of CYP27A1 and subsequent production of $27 \mathrm{HC}$ are insufficient to induce a phenotype under these circumstances.

Interestingly however, addition of exogenous $27 \mathrm{HC}$ dose-dependently decreased cellular proliferation of several ovarian cancer models, including ID8, MOE, HEY A8 and ES2 (Fig. 2D, E, F and Fig. 3A, B, C, D). The dose dependence was also confirmed over a broader range of doses
(Fig. 2G, H, I and J). We speculated that the antiproliferative activity of $27 \mathrm{HC}$ was either being mediated by its ability to bind to the Insig-1:SCAP complex and thus inhibiting SREBP-2 activation and subsequent cholesterol synthesis and uptake or through LXR activation and subsequent cholesterol efflux.

In support of an LXR mediated effect, treatment with the synthetic LXR agonist, GW3965, also decreased the proliferation of ovarian cancer lines, albeit to a lesser degree than 27HC (Fig. 3A, B, C and D). These effects were not due to overt cytotoxicity of $27 \mathrm{HC}$ or GW3965 as cell viability assessed after overnight treatment was not altered, as determined by the MTT assay (Fig. 3E). When an active nuclear form of SREBP-2 (nSREBP-2) was expressed, there was a significant induction of known SREBP-2 target genes, as expected (HMGCR, LDLR, HMGCS, Insig-1 and SQLE; Fig. 3F). Treatment with reported activators of SREBP-2, haloperidol (Hal) and clozapine (Clo) also resulted in induction of SREBP-2 target genes (Ferno et al. 2005). On the other hand, Betulin (Bet), a known inhibitor of SREBP (Tang et al. 2011) reduced the expression of SREBP-2 target genes (Fig. 3F). While 27HC modestly reduced these target genes, they robustly induced known LXR target genes (ABCA1, ABCG1 and SREBP1-c). This induction was lost when $\operatorname{LXR} \alpha$ and $\beta$ were knocked down with siRNA (Fig. 3F). Importantly, the antiproliferative effects of $27 \mathrm{HC}$ persisted, even in the presence of nSREBP-2, or in the presence of the SREBP-2 activators, Hal or Clo (Fig. $3 \mathrm{G}$ and $\mathrm{H}$ ). On the other hand, knockdown of the LXRs (70\% knockdown of LXR $\alpha$, $58 \%$ knockdown of LXR $\beta$ ), resulted in the loss of the inhibitory effects of $27 \mathrm{HC}$ on proliferation (Fig. 3I). 

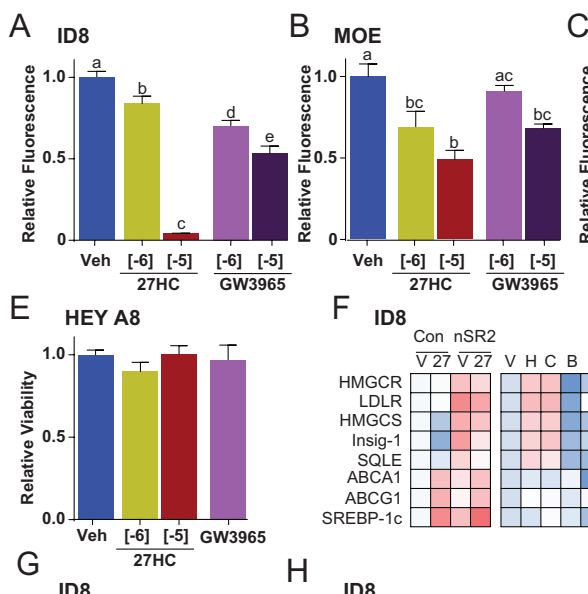

C HEY A8

D ES2

F ID8
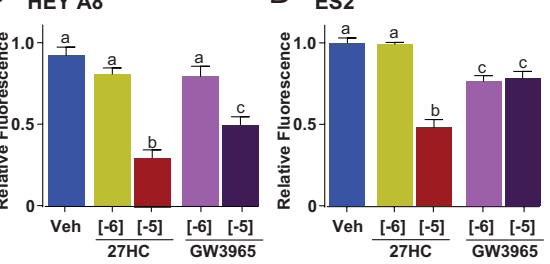

$\begin{array}{lll}\mathrm{HC} & & \\ ++ & 27 \mathrm{HC} & \text { SiC silXRsier }\end{array}$
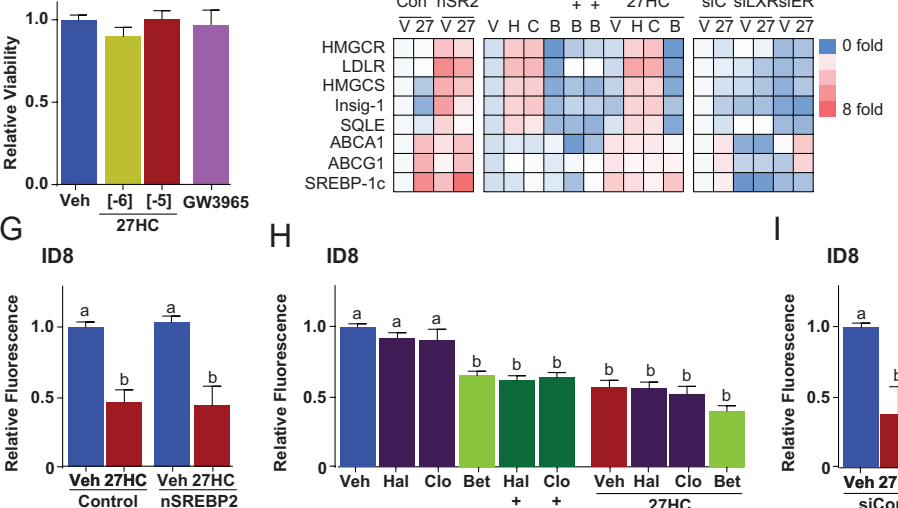

ID8

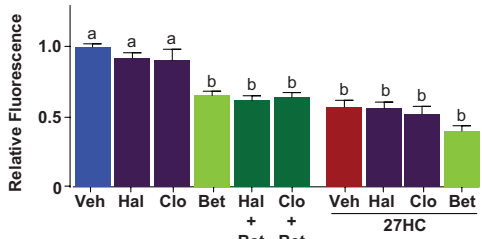

Bet Bet

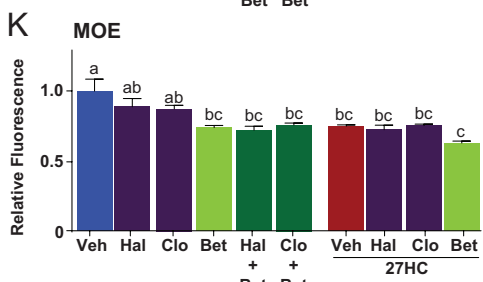

Bet Bet

N HEY A8

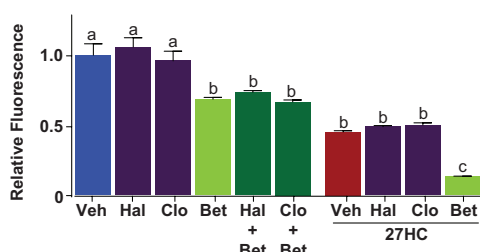

Q HEY A8

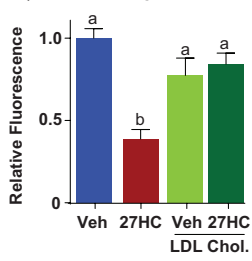

ID8

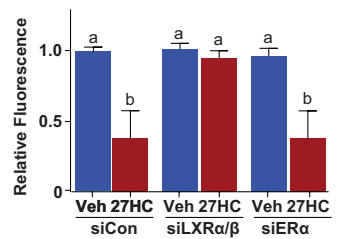

L MOE

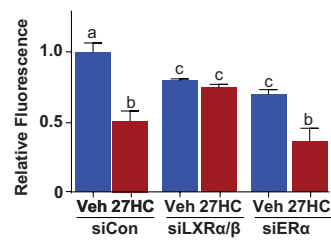

O HEY A8

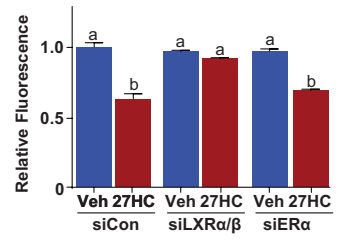

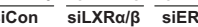

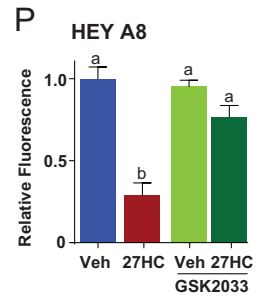

Figure 3

27HC decreases ovarian cancer cell proliferation via activation of the LXRs and subsequent cholesterol efflux. (A, B, C and D) Similar to 27HC, a synthetic LXR agonist, GW3965, also decreases proliferation of ID8, MOE, HEY A8 and ES2 cells. (E) 27HC or GW3965 do not significantly alter cell viability as assessed by an MTT assay. (F) Heat map indicating gene expression changes of ID8 cells as assessed by quantitative PCR (QPCR). Left Panel: ID8 cells were transfected with a control vector, or one encoding a constitutively active nuclear SREBP-2 form (nSR2, nSREBP-2) and treated with either vehicle or 27HC $(\mathrm{V}, 27)$. Middle Panel: ID8 cells were treated with the SREBP-2 activators haloperidol $(\mathrm{H}, \mathrm{Hal})$, clozapine $(\mathrm{C}, \mathrm{Clo})$, or the inhibitor Betulin (B, Bet), in the presence or absence of 27HC. Right Panel: ID8 cells were transfected with control siRNA (SiC), siRNA against LXR $\alpha / \beta$ (siLXR) or siRNA against ER $\alpha$ (siER), and then treated with either vehicle or 27HC. A scale for the heat map is located on the far right. Classic SREBP-2 target genes include HMGCR, LDLR, HMGCS, Insig-1 and SQLE. Classic LXR target genes include ABCA1, ABCG1 and SREBP-1C. (G, H and I) Proliferation of ID8 cells under the same experimental conditions as described for $(F)$ indicates that the effects of $27 \mathrm{HC}$ depend on the expression of the LXRs. (J, K, L and M, N, O) Parallel experiments were performed on MOE and HEY A8 cells respectively, yielding similar results. (P) Inhibition of proliferation by $27 \mathrm{HC}$ is attenuated by co-treatment with the LXR antagonist GSK2033 in HEY A8 cells. (Q) Inhibition of proliferation by $27 \mathrm{HC}$ is attenuated by supplementation with exogenous LDL cholesterol. One-way ANOVA followed by student Newman-Keul's test was used for statistical analysis, with different letters indicating significant differences between groups ( $P<0.05$, as in a is different than $b$, but ab is not different from either a or b). 
Knockdown of ER $\alpha$ (75\% knockdown) had no impact on the effects of $27 \mathrm{HC}$ in this context. These findings were consistent across three ovarian cancer cell lines, representing both human derived and murine derived: ID8, MOE and HEY A8 (Fig. 3G, H, I, J, K, L, M, N and $\mathrm{O})$. Finally, the anti-proliferative effects of $27 \mathrm{HC}$ were attenuated when HEY A8 cells were co-treated with a small-molecule antagonist of LXR (GSK2033, Fig. 3P).

Collectively, although the involvement of SREBP-2 cannot be ruled out, it appears that in terms of proliferation, the effects of $27 \mathrm{HC}$ require the LXRs. Since LXR activation generally promotes cholesterol efflux, we tested whether the inhibitory effects of $27 \mathrm{HC}$ were due to cholesterol depletion. Indeed, the decrease in proliferation caused by $27 \mathrm{HC}$ could be rescued by addition of exogenous LDL cholesterol (Fig. 3Q), suggesting that the inhibition of proliferation was due to the cellular deficiency of cholesterol. The inhibitory effects of $27 \mathrm{HC}$ being mediated through the LXRs is contrary to what has been reported in prostate cancer where engagement of SREBP was implicated as the mechanism of antiproliferation (Alfaqih et al. 2017).

Interestingly, cell lines that express ER appeared resistant to the inhibitory effects of 27HC (OVCAR3, $\mathrm{CaOV} 3$ and PEO4, Supplementary Fig. 3A, B and C). In fact, 27HC stimulated the proliferation of $\mathrm{PEO} 4$ cells, a line that highly expresses ER $\alpha$ and is also stimulated by estradiol. Intriguingly however, when ER signaling was blocked by ICI 182780 (fulvestrant), 27HC inhibited proliferation, suggesting that the actions of ER could overcome those of the LXRs. Regardless, the anti-proliferative properties of 27HC were in apparent contrast to the human survival data (Fig. 1C and F). Therefore, since the clinical data support a role for $27 \mathrm{HC}$ in promoting the progression of ovarian cancer, we conclude that the cancer cell-intrinsic activities of $27 \mathrm{HC}$ are unlikely to explain its effects.

\section{HC increases peritoneal colonization and imparts chemoresistance}

The direct effects of $27 \mathrm{HC}$ on ovarian tumor progression were evaluated by treating mice engrafted with MOE tumors with exogenous 27HC. MOE cells were generated by overexpressing an activating mutant of KRAS (KRASG12V) and shRNA to knockdown PTEN in epithelial cells harvested from the oviduct of FVB mice (Eddie et al. 2015). When grafted orthotopically, they form large primary tumors and spread throughout the peritoneum, recapitulating human disease. $27 \mathrm{HC}$ did not have a
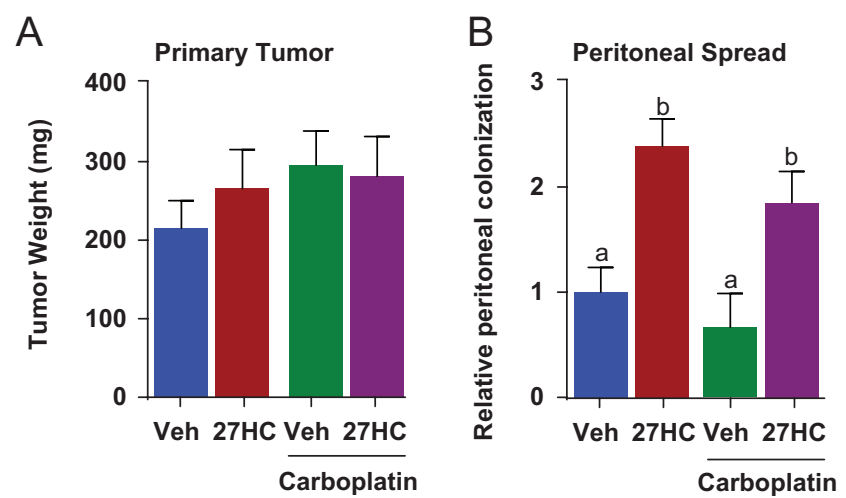

C
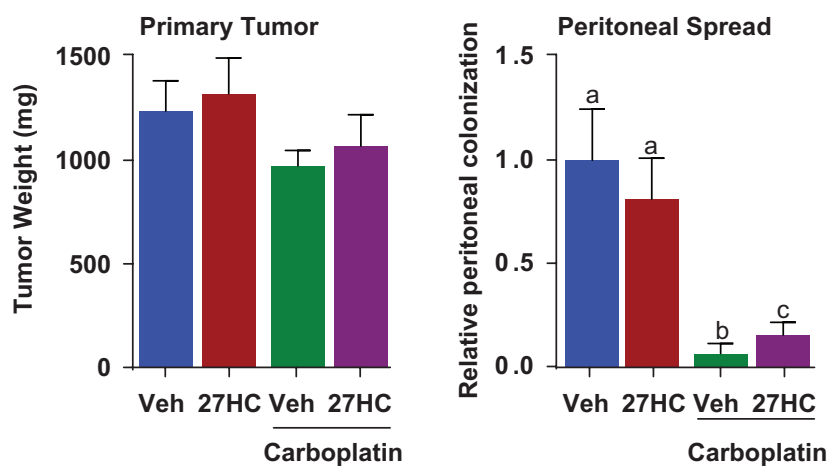

\section{Figure 4}

$27 \mathrm{HC}$ increases peritoneal spread of ovarian cancer and imparts resistance to carboplatin. (A) Primary tumor weight of MOE grafts at an early stage, being treated with a low dose of carboplatin $(16 \mathrm{mg} / \mathrm{kg}$ every 4 days). (B) Relative peritoneal nodules resulting from MOE tumors in (A). (C) Primary tumor weight of MOE grafts at a late stage, being treated with a higher dose of carboplatin (40 mg/kg every 4 days). (D) Relative peritoneal spread resulting from MOE tumors in (C). Different letters denote statistical significance $(P<0.05$, one-way ANOVA followed by student Newman-Keuls test).

significant effect on the resulting primary tumor size; however, it did robustly increase the number of peritoneal nodules found throughout the peritoneal space at an early time-point (Fig. 4). Low-dose carboplatin therapy was not effective in treating the primary tumor. However, 27HC continued to promote peritoneal colonization even in the presence of this low-dose regimen of carboplatin, when tumors were assessed at an early stage time point (Fig. 4B). The chemoprotective effects of $27 \mathrm{HC}$ were also observed at a later stage time point when a higher dose of carboplatin was used (Fig. 4D). Evaluation of representative gene expression is detailed in Supplementary Table 2. These data indicate that (1) the effects of $27 \mathrm{HC}$ may be most apparent at times and sites where the microenvironmental niche or immune-suppression has not been fully established and (2) the basal levels of $27 \mathrm{HC}$ may be sufficient to support ovarian tumor progression.
C) 2019 Society for Endocrinology Published by Bioscientifica Ltd. Printed in Great Britain 
A

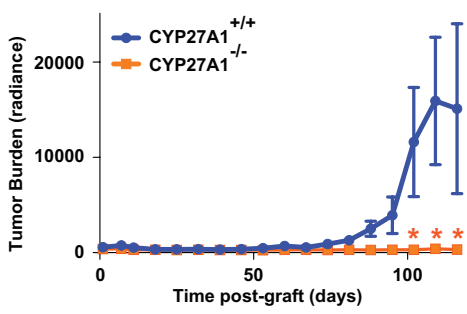

E

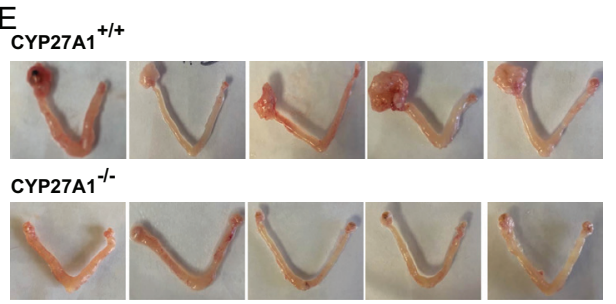

B

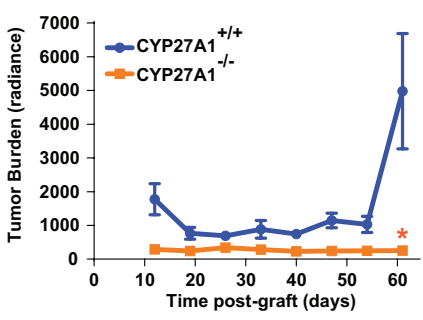

$\mathrm{F}$

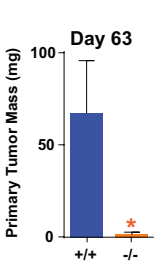

C

G

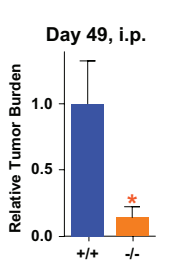

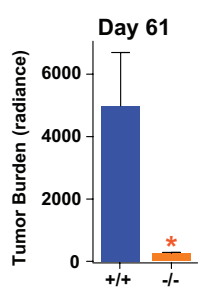

D

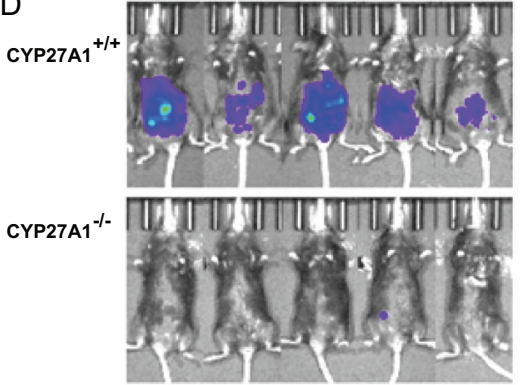

$\mathrm{H}$

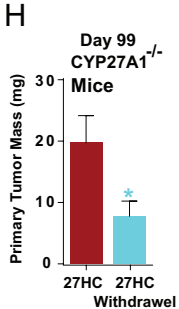

\section{Figure 5}

Tumors fail to thrive in mice lacking CYP27A1. (A) Luciferase tagged ID8 murine ovarian cancer cells (ID8-luc) were orthotopically grafted into the anterior left ovary/bursa area of C57BL/6 mice at Day 0 . Tumor growth was monitored with bioluminescent imaging. A representative image of these mice is depicted in Supplementary Fig. 4. (B) The experiment in (A) was repeated in a separate cohort of mice, yielding similar results. (C) Tumor burden at Day 61 as assessed by bioluminescent imaging, from the experiment in (B). (D) Representative images of luciferase expression at Day 61 , from the experiment in (B). (E) Representative images of tumor ovary (left side), uterus and control ovary (right side) at the end of the experiment (Day 63), from the experiment in (B). (F) Primary tumor weight at experiment endpoint (Day 63), from the experiment in (B). (G) ID8 grafts fail to thrive when introduced by intraperitoneal (i.p.) injection. ID8 cells were injected into the peritoneal space and followed through time by bioluminescent imaging. Bioluminescence at day 49 post-graft is depicted here. The corresponding time course is included in Supplementary Fig. 5. (H) CYP27A1-/- mice were supplemented with $27 \mathrm{HC}(20 \mathrm{mg} / \mathrm{kg} /$ day) starting 5 days prior to tumor engraftment. At Day 0, ID8-luc murine ovarian cancer cells were grafted into one ovary/bursa of the mice. At day 74, mice were randomized into two groups with the $27 \mathrm{HC}$ group continuing to receive $27 \mathrm{HC}$ while $27 \mathrm{HC}$ Withdraw group received vehicle instead. The final tumor mass was determined at day 99 . Statistical analysis for A and B was performed with two-way ANOVA followed by a Bonferroni multiple comparison test or Student $T$-test. Two-tailed $T$ tests were used for $\mathrm{C}$, and F-H. Asterisks indicate statistical significance $(P<0.05)$.

\section{CYP27A1 is required for ovarian tumor growth}

Since 27HC generally inhibited cellular proliferation of ovarian cancer cells and exogenous 27HC appeared to impact only the peritoneal spread of tumors, we wanted to evaluate whether basal concentrations of 27HC acted on the host to facilitate tumor growth. Therefore, we grafted otherwise unaltered ID8-luc cells into the ovarian bursal region of either wildtype mice or CYP27A1-/- mice. Strikingly, while grafts were initially present to similar degrees as determined by bioluminescent imaging, those tumors grown in CYP27A1-/- mice quickly regressed to the point where at necropsy tumors were no longer detected, while large tumors were found in wild-type mice (Fig. 5A and Supplementary Fig. 4). Evaluation of representative gene expression is detailed in Supplementary Table 2. Given these striking results, we repeated this study in a second cohort of mice, obtaining similar results, in that ID8 grafts failed to thrive in CYP27A1-/- mice, as confirmed by bioluminescent imaging, visually, and by tumor weight (Fig. 5B, C, D, E and F).
C 2019 Society for Endocrinology Published by Bioscientifica Ltd. Printed in Great Britain
Using a common approach to model colonization of disseminated ovarian cancer cells, we grafted ID8 cells intraperitoneally and followed total tumor burden through time. Recapitulating the results obtained when cells were grafted into the ovarian bursa region, total tumor burden was significantly reduced in mice lacking the expression of CYP27A1, 49 days post intraperitoneal injection of ID8 cells (Fig. 5G and Supplementary Fig. 5).

In order to determine whether the product of CYP27A1, 27HC, was mediating these effects, we again grafted ID8 cells into the ovarian bursa of CYP27A1-/mice, but chronically treated these mice with exogenous $27 \mathrm{HC}$. Indeed, lack of $27 \mathrm{HC}$ was deemed to be the reason for this observed phenotype, at least in part, since treatment of CYP27A1-/- mice with exogenous $27 \mathrm{HC}$ was able to maintain tumors, and its subsequent withdrawal resulted in tumor regression (Fig. 5H). However, the significantly smaller size of tumors grown in CYP27A1-/mice supplemented with $27 \mathrm{HC}$ suggests either (1) $27 \mathrm{HC}$ is only a contributing factor, and other metabolites of CYP27A1 are also important for tumor establishment and growth, and/or (2) global and early loss of CYP27A1 
results in permanent developmental defects that can only be partially rescued by exogenous $27 \mathrm{HC}$. These data strongly suggest that CYP27A1 and its product, $27 \mathrm{HC}$ are required for the establishment of a hospitable tumor microenvironment.

\section{HC alters abundance of tumoral myeloid immune cells}

It has been appreciated for several years now that different myeloid cell populations within the tumor microenvironment, promote tumor progression (Sica et al. 2008). Specific to ovarian cancer, it has been shown that increased myeloid cell infiltration is associated with higher grade (III and IV) tumors as well as decreased survival (Milne et al. 2012, Fialova et al. 2013). Given our results indicating that the expression of CYP27A1 was required to sustain ovarian tumors, as well as previous reports indicating that CYP27A1 is highly expressed in myeloid immune cells (Nelson et al. 2013, He \& Nelson 2017), we therefore investigated whether CYP27A1 loss or exogenous $27 \mathrm{HC}$ altered tumoral myeloid cell abundance. Specifically, tumors in CYP27A1-/- mice had fewer CD11B+ cells, a general myeloid cell marker (Fig. 6A). Unfortunately, due to lack of tumor development and thus limited material for flow cytometry, further staining of myeloid cell subtypes could not be done with confidence due to the small number of events. However, analysis of tumors from 27HC-treated mice did reveal differences in several immune populations. Of note, $27 \mathrm{HC}$ treatment resulted in an increased presence of monocytic myeloidderived suppressor cells (M-MDSC) (CD11B+, Ly6C+, IA/IE-; Fig. 6B). Other myeloid populations were also altered: a small population of immature macrophages $(\mathrm{CD} 11 \mathrm{~B}+$, Ly6C+, IA/IE+) were increased by $27 \mathrm{HC}$, while antigen-presenting macrophages $(\mathrm{CD} 11 \mathrm{~B}+$, Ly6C-, $\mathrm{IA} / \mathrm{IE}+$ ) were decreased (Fig. 6C and D). On the other hand, upon analysis of spleens isolated from CYP27A1-/- mice of Fig. 5A, we observed decreased M-MDSCs and increased antigen-presenting macrophages (Supplementary Fig. 4C). Although tumoral cytotoxic $\mathrm{CD}^{+} \mathrm{T}$ cells were not significantly altered, CD4 ${ }^{+} \mathrm{T}$ cells were decreased by $27 \mathrm{HC}$ and a very small population of less well-defined $\mathrm{CD}^{+}, \mathrm{CD}^{+}$double-positive cells were also decreased (Fig. 6E, F and G). Correspondingly, in the lymph nodes of CYP27A1-/- mice from Fig. 5A, we observed similar level of CD8+ T cells and increased CD4+ T cells, compared to CYP27A1 ${ }^{+/+}$mice (not shown).

Interestingly, while it has previously been demonstrated that $27 \mathrm{HC}$ increases neutrophils
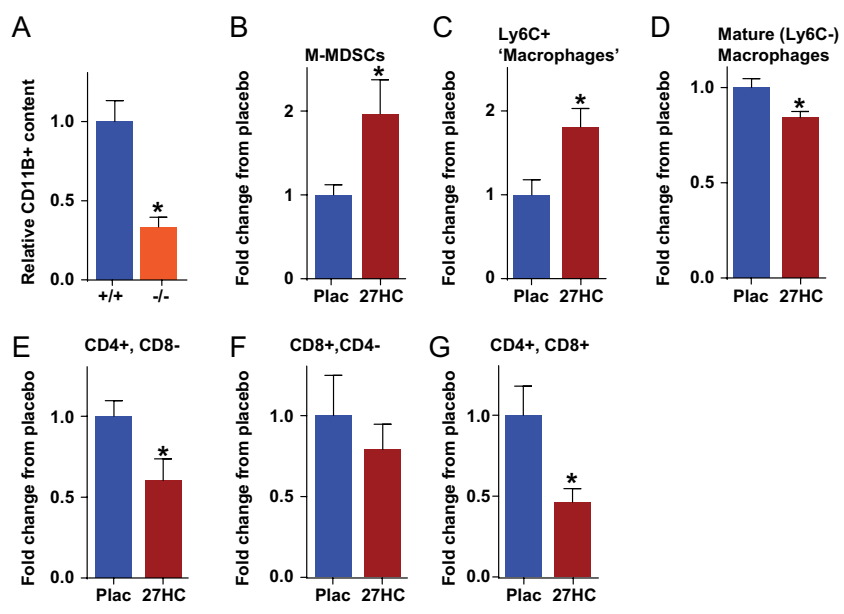

\section{$\mathrm{G} \quad \mathrm{CD} 4+, \mathrm{CD} 8+$}
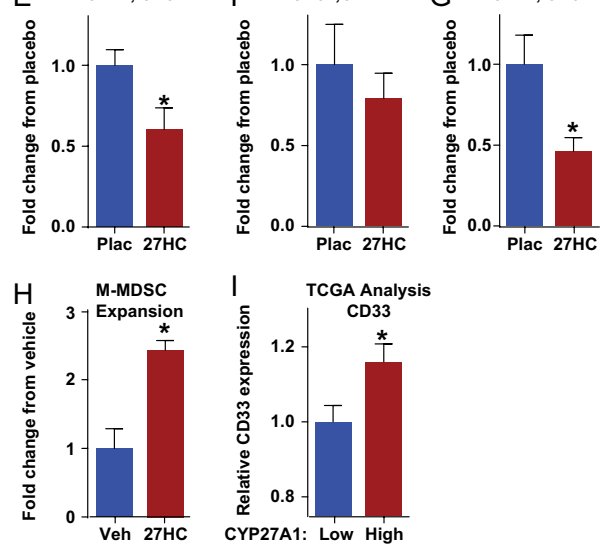

\section{Figure 6}

$27 \mathrm{HC}$ alters immune cell populations within ovarian tumors and promotes the differentiation of M-MDSCs. (A) Tumors grown in wildtype mice had significantly more CD11B+ myeloid cells compared to ovarian tissue from CYP27A1-/- mice. (B, C, D, E, F and G) $27 \mathrm{HC}$ treatment resulted in alterations of the indicated immune cell populations. $(\mathrm{H}) 27 \mathrm{HC}$ stimulated the in vitro differentiation of M-MDSCs from bone marrow progenitors in the presence of IL6 and GM-CSF. (I) Microarray expression data for 551 ovarian cancer patients was accessed and parsed based on median expression of CYP27A1, into low and high groups. Expression of CD33, a human marker of M-MDSCs was plotted. Asterisks indicate statistical significance $(P<0.05)$.

(same markers as granulocytic myeloid derived suppressor cells MDSCs) in metastatic breast cancer (Baek et al. 2017), we did not find evidence of this population at any significant levels within the tumors of ID8 or MOE models. Analysis of immune tissues from cancer-naïve mice revealed that M-MDSCs were elevated within the bone marrow and peritoneal lymph nodes of CYP27A1-1- mice, although there was no change in this population within the spleen (Supplementary Fig. 6). Increased M-MDSCs observed in CYP27A1-/- mice is opposite to what would have been expected given the increased presence of M-MDSCs in the tumors of mice treated with $27 \mathrm{HC}$, suggesting that the presence of tumors is required to provide the right environmental cues for 27HC to increase M-MDSCs. Other populations in naïve mice were also modestly altered in CYP27A1-/mice (Supplementary Fig. 6).

Given the increased abundance of myeloid cells and in particular M-MDSCs, we hypothesized that 27HC 
may enhance their differentiation from bone marrow precursors. Therefore, we differentiated bone marrowderived cells with GM-CSF and IL6 in the presence or absence of $27 \mathrm{HC}$. Indeed, $27 \mathrm{HC}$ increased the proportions of Ly6C+ M-MDSCs compared to vehicle (Fig. 6H). In order to establish the human relevance of our preclinical findings, we accessed microarray expression TCGA data (Provisional Ovarian Serous Cystadenocarcinoma set). Data from 551 patients were parsed based on the median expression of CYP27A1. It was found that the expression of a human M-MDSC marker, CD33, was significantly higher in patients with high CYP27A1 expression (and thus expected to be increased local 27HC), thereby highlighting the clinical significance of our results (Fig. 6I).

\section{CYP27A1 expression within bone marrow-derived cells required to support ovarian tumors}

In order to specifically test whether a myeloid cell component was involved in the failure of tumors to thrive in CYP27A1-/- mice, we performed an experiment where bone marrow from either wildtype or CYP27A1-/- mice was transplanted into lethally irradiated CYP27A1-/mice. Subsequently, after a time period allowing for complete regeneration of the bone marrow derived cell repertoire, ID8 cells were grafted. In strong support of the hypothesis that CYP27A1 expression within myeloid cells is required for an environment facilitative of ovarian cancer, we found that tumors grew far more robustly in CYP27A1 $1^{--}$mice that had received marrow from wild-type mice (Fig. 7A). Peritoneal colonization was also more apparent in mice that had received wild-type marrow (Fig. 7B).

\section{Combined inhibition of CYP27A1 and immune checkpoint results in decreased tumor growth}

Our evidence strongly suggests that myeloid expression of CYP27A1 was required to create a microenvironment hospitable for the growth of ovarian cancer. MDSCs have the capacity to suppress the acquired immune system in both checkpoint dependent and independent mechanisms. Our data indicating that 27HC treatment altered $\mathrm{T}$ cell populations is supportive of this notion. On the other hand, although the success of immune checkpoint inhibitor therapy in certain cancers has revolutionized how we think about cancer immunetherapy, and while some ovarian cancer patients show remarkable response, the majority do not display significant clinical benefit (Gaillard et al. 2016, Hamanishi et al. 2016). Both myeloid cell and $\mathrm{T}$ cell infiltration have been reported as prognostic factors associated with checkpoint inhibitor success. Therefore, we hypothesized that inhibition of CYP27A1 and thus M-MDSCs may enhance the therapeutic potential of checkpoint inhibitors. MOE cells were grafted into the bursa/ovary of mice and allowed to establish for 7 days. Based on a pilot study, the mean tumor size at this point would be $\sim 25 \mathrm{mg}$. Mice were then treated with a small-molecule inhibitor of CYP27A1, GW273297X, anti-PD-L1 ( $\alpha$-PD-L1) or both. GW273297X at this dose has been shown to significantly reduce circulating $27 \mathrm{HC}$ concentrations (Nelson et al. 2013, Baek et al. 2017). $\alpha$-PD-L1 was dosed intraperitoneally every 2 days, a strategy previously shown to stably disrupt this checkpoint (Kleffel et al. 2015, Lau et al. 2017). Intriguingly, while neither single treatment with GW273297X nor $\alpha$-PD-L1 significantly altered tumor size, their combined treatment significantly reduced primary tumor burden (Fig. 8). Further work will
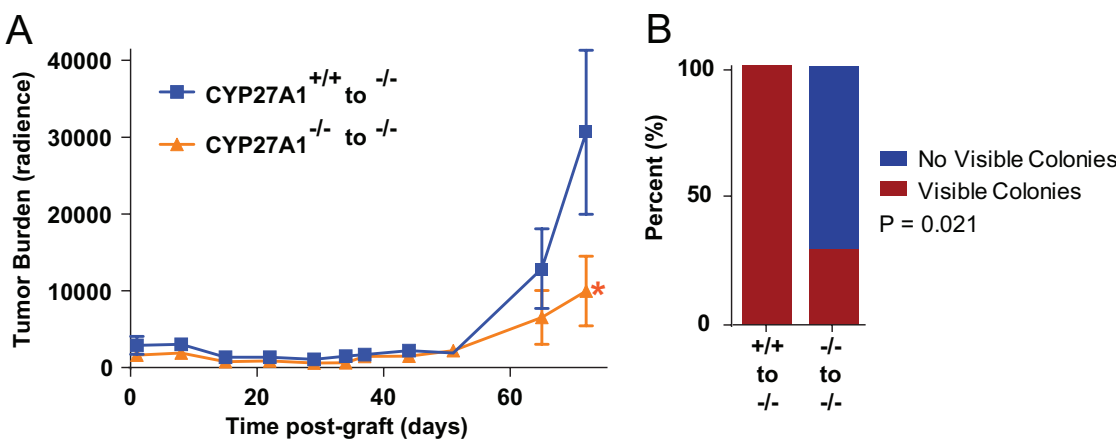

\section{Figure 7}

Wildtype bone marrow transplant is sufficient to allow ID8 tumors to grow in CYP27A1-/- mice. CYP27A1-/- mice were irradiated and transplanted with wildtype (+/+) or CYP27A1-/bone marrow. After allowing sufficient time for donor bone marrow to reconstitute all cell lineages, luciferase tagged ID8 murine ovarian cancer cells (ID8-luc) were orthotopically grafted into one ovary/bursa of mice. (A) Tumor growth was monitored by bioluminescent imaging throughout the study, and (B) peritoneal colonization was assessed at necropsy (day 74). Statistical analysis was performed with two-way ANOVA with Bonferroni multiple comparison test $(A)$ or Fisher's exact test (B). Asterisks indicate statistical significance $(P<0.05)$. 


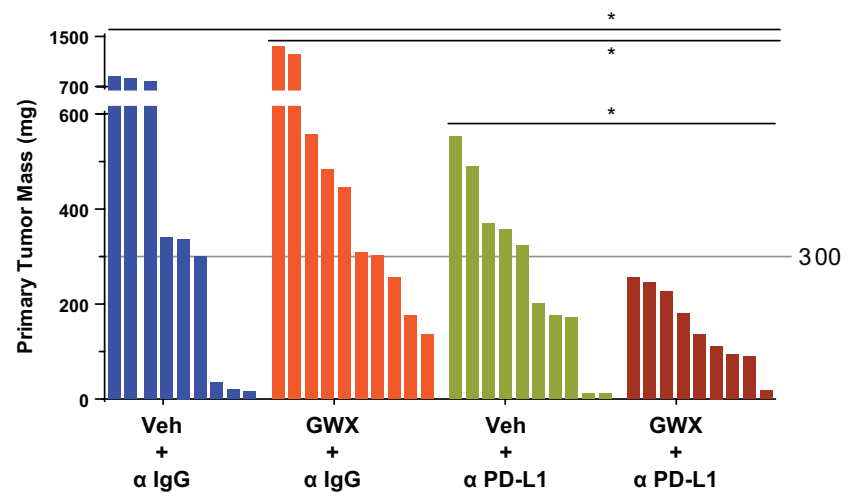

Figure 8

CYP27A1 inhibition in combination with immune checkpoint inhibition reduces primary tumor volume. MOE murine ovarian cancer cells were orthotopically grafted into one ovary/bursa of FVB/N mice on Day 0. Starting from Day 7, mice were treated intraperitoneally with Veh or 100 mg/kg CYP27A1 inhibitor (GW273297X) daily. IgG2b control or $200 \mu \mathrm{g}$ anti-PDL1 were injected intraperitoneally on days 10, 12, 14, 16, 18, 20, 22. A waterfall plot is presented here, with each mouse represented by a bar. The grey line indicates the chosen cutoff indicating a positive response (tumors less than $300 \mathrm{mg}$ ). A Fisher's exact test was used to determine whether there were differences in response as assessed by tumors less than $300 \mathrm{mg}$

be required to elucidate the precise pharmacologic nature of this interaction between checkpoint inhibition and inhibition of CYP27A1.

\section{Discussion}

Patients diagnosed with ovarian cancer continue to have a very poor survival rate. This is in part due to de novo and acquired resistance to current standard of care. Furthermore, despite the great potential of immunetherapy, ovarian cancer patients typically do not respond to checkpoint inhibition. On top of these shortcomings, ovarian cancer has a microenvironment and mechanism of metastasis (peritoneal colonization) unique to other solid tumors, with cells being able to disseminate directly into the peritoneal space in addition to entering the blood stream (Barbolina et al. 2009, Pradeep et al. 2014, van Baal et al. 2018). Therefore, there is significant need to better understand the ovarian cancer microenvironment as well as develop modulators that improve the efficacy of treatment.

In this regard, it was intriguing that obesity is associated with decreased PFS and DSS. In this context, a common comorbidity of obesity, elevated LDL-cholesterol, is also a poor prognostic marker (Li et al. 2010). On the other hand, statin therapy is associated with increased survival (Elmore et al. 2008, Lavie et al. 2013, Habis et al. 2014, Akinwunmi et al. 2019). In our preclinical murine model, a dietary increase in cholesterol modestly increased ovarian tumor growth, supporting the retrospective data implicating cholesterol in the pathophysiology of ovarian cancer. However, the observed modest increase would suggest that basal cholesterol levels are sufficient to promote tumor progression, a notion supported by retrospective data indicating that statin therapy increases PFS. While statins are fairly well tolerated and effectively reduce circulating cholesterol, evidence from atherosclerosis and breast cancer indicates that tissues distal from the liver upregulate HMGCoA-reductase (Bjarnadottir et al. 2013). Since the target tissue of statins is the liver, and most statins circulate at concentrations far below the $\mathrm{EC}_{50}$ for HMGCoA-reductase, the upregulation of this enzyme likely results in a local supply of cholesterol, thereby potentially limiting the therapeutic efficacy of this target, at least with respect to cancer (Nelson 2018). Therefore, pursuit of downstream targets of cholesterol action is warranted. Being a primary metabolite of cholesterol that circulates at concentrations approaching its $\mathrm{EC}_{50}$ for both the ERs and LXRs, 27HC represents one such potential target (He \& Nelson 2017). A role for 27HC in ovarian cancer progression was supported by data indicating that the expression of enzymes responsible for the synthesis and catabolism of $27 \mathrm{HC}$ are associated with differences in survival (Fig. 1).

Given the clinical data in support of a pathological role for $27 \mathrm{HC}$ in ovarian cancer, it was somewhat counterintuitive that this metabolite inhibited cell proliferation. The dependence of these effects on LXR was contrary to what has been found in 22RV1 prostate cancer cells where SREBP2 overexpression could partially rescue the effects of 27HC (Alfaqih et al. 2017), indicating that either of the mechanisms are dependent on the cellular context or that SREBP2 is able to attenuate the actions of LXR. Regardless, the associations of 27HC-related enzymes and ovarian cancer outcomes prompted us to interrogate the potential role of $27 \mathrm{HC}$ in regulating the tumor microenvironment. The regression of ID8 tumors in CYP27A1-/- mice in a $27 \mathrm{HC}$ dependent manner, coupled with the ability of ID8 grafts to grow in CYP27A1-/- who had received wild-type bone marrow transplants strongly support this concept. Addition of exogenous 27HC did not have striking effects on the primary tumor, but did increase peritoneal colonization and confer some resistance to carboplatin. Collectively, this indicates that even basal levels of $27 \mathrm{HC}$ are sufficient to support ovarian tumor growth and that extra-ovarian sites of colonization or tumors that are not as well established are most influenced by $27 \mathrm{HC}$. 
We further found that $27 \mathrm{HC}$ promoted the differentiation of M-MDSCs and mice treated with 27HC had increased M-MDSCs within their tumors, indicating that these cells are likely mediators of this effect. Highlighting the likely clinical significance of our findings, we found that CYP27A1 expression was correlated with the expression of a human MDSC marker (CD33, Fig. 6I). Interestingly, we have recently found that $27 \mathrm{HC}$ increases the presence of polymorphonuclear neutrophils (PMNs) at the metastatic sites of breast cancer (Baek et al. 2017). The markers used to identify this population are the same used for granulocytic (G)-MDSCs $\left(\mathrm{CD} 11 \mathrm{~B}^{+}, \mathrm{Ly}_{6 \mathrm{G}}{ }^{+}\right.$). Immune depletion experiments found that the presence of PMNs was critical for the pro-metastatic effects of $27 \mathrm{HC}$ in breast cancer. However, we did not find significant tumoral infiltration of PMNs in either of our murine models of ovarian cancer (ID8 or MOE), regardless of 27HC treatment. Thus, the microenvironmental context is likely important with respect to the actions of $27 \mathrm{HC}$.

The fact that $27 \mathrm{HC}$ is a ligand for both the ERs and LXRs coupled with the observed increased differentiation of M-MDSCs in the presence of $27 \mathrm{HC}$ is intriguing given recent reports that an ER agonist (estradiol) increases MDSC infiltration of ovarian tumors and that synthetic LXR agonists (GW3965 and RGX-104) can reprogram MDSCs to activate the tumor immune response (Svoronos et al. 2017, Tavazoie et al. 2018). This would suggest that 27HC may be working as either an ER agonist or LXR antagonist or both. However, both 27HC and GW3965 induce ABCA1, a classic LXR target gene within myeloid cells, suggesting that it is an LXR agonist. Therefore, future work will be required to elucidate the precise receptormediated contributions to the M-MDSC effects by 27HC.

MDSCs can function in several ways to facilitate cancer progression, including angiogenesis, immune suppression and secretion of cytokines that can serve to protect ovarian cancer cells from apoptosis, ultimately conveying chemotherapy resistance (Kryczek et al. 2006, 2007, Robinson-Smith et al. 2007, Castells et al. 2012). This is one potential mechanism for the observed resistance to carboplatin observed in mice treated with $27 \mathrm{HC}$. Furthermore, M-MDSCs are known to suppress antitumor immunity in addition to other pro-tumorigenic roles (Kong et al. 2013). We have observed decreases in $\mathrm{CD}^{+}{ }^{+} \mathrm{T}$ cell infiltrate in tumors from mice treated with $27 \mathrm{HC}$, suggesting that $27 \mathrm{HC}$ actively suppresses anticancer immunity. Although this mechanism remains to be formally tested, the rejection of tumor grafts in CYP27A1-/- mice, coupled with the sensitization of immune checkpoint inhibition by an inhibitor of CYP27A1, are highly suggestive that the acquired immune system is involved.

The paradoxical nature of $27 \mathrm{HC}$ both inhibiting cellular proliferation, but at the same time promoting a microenvironment conducive to ovarian cancer establishment and growth, may be reflected in our analysis of patient data. More specifically, it was found that CYP27A1 expression was a poor prognostic in terms of overall survival in patients who were diagnosed with early stage ovarian cancer, while its expression was good prognostic for patients with late stage disease (Fig. 1). This could indicate that at early stages, the M-MDSC promoting activities of $27 \mathrm{HC}$ are dominant, while after the tumor has established and already created a suitable microenvironment, the anti-proliferative effects of $27 \mathrm{HC}$ become more apparent. This notion is supported by our observations that it is the basal concentrations of $27 \mathrm{HC}$ that appear to be required for tumor establishment and growth, and that addition of exogenous $27 \mathrm{HC}$ had minimal impact on tumor growth. Future work will be required to further elucidate this paradox.

In summary, while elevating dietary cholesterol or treating with exogenous $27 \mathrm{HC}$ modestly increases the progression of ovarian tumors, their basal levels in normo-cholesterolemic mice are likely already sufficient to support tumor growth. However, ovarian tumors fail to thrive in mice lacking CYP27A1, the enzyme responsible for the synthesis of $27 \mathrm{HC}$, likely due to the improper differentiation and/or function of M-MDSCs. This opens up the possibility of targeting this axis in conjunction with immune-therapy. Preclinical data indicating the sensitization of tumors to $\alpha$-PD-L1 by an inhibitor of CYP27A1 inhibitor and strongly supports this approach.

\section{Supplementary data}

This is linked to the online version of the paper at https://doi.org/10.1530/ ERC-18-0572.

Declaration of interest

The authors declare that there is no conflict of interest that could be perceived as prejudicing the impartiality of the research reported.

\section{Funding}

This work was supported by the National Cancer Institute of the National Institutes of Health (R00CA172357, R01CA234025 (E R N) and T32EB019944 $(\mathrm{S} H))$, and a Cancer Scholars for Translational and Applied Research (C*STAR) Award (S H).
(C) 2019 Society for Endocrinology Published by Bioscientifica Ltd. Printed in Great Britain 


\section{References}

Akinwunmi B, Vitonis AF, Titus L, Terry KL \& Cramer DW 2019 Statin therapy and association with ovarian cancer risk in the New England Case Control (NEC) Study. International Journal of Cancer $\mathbf{1 4 4}$ 991-1000. (https://doi.org/10.1002/ijc.31758)

Alfaqih MA, Nelson ER, Liu W, Safi R, Jasper JS, Macias E, Geradts J, Thompson JW, Dubois LG, Freeman MR, et al. 2017 CYP27A1 loss dysregulates cholesterol homeostasis in prostate cancer. Cancer Research 77 1662-1673. (https://doi.org/10.1158/0008-5472.CAN-16-2738)

Amend SR, Valkenburg KC \& Pienta KJ 2016 Murine hind limb long bone dissection and bone marrow isolation. Journal of Visualized Experiments. (https://doi.org/10.3791/53936)

American Cancer Society 2019 Cancer Facts \& Figures 2019. Atlanta, GA, USA: American Cancer Society. (available at: https://www.cancer.org/ research/cancer-facts-statistics/all-cancer-facts-figures/cancer-factsfigures-2019.html)

Baek AE, Yu YA, He S, Wardell SE, Chang CY, Kwon S, Pillai RV, McDowell HB, Thompson JW, Dubois LG, et al. 2017 The cholesterol metabolite 27 hydroxycholesterol facilitates breast cancer metastasis through its actions on immune cells. Nature Communications 8864 . (https://doi.org/10.1038/s41467-017-00910-z)

Barbolina MV, Moss NM, Westfall SD, Liu Y, Burkhalter RJ, Marga F, Forgacs G, Hudson LG \& Stack MS 2009 Microenvironmental regulation of ovarian cancer metastasis. Cancer Treatment and Research 149 319-334. (https://doi.org/10.1007/978-0-387-98094-2_15)

Bjarnadottir O, Romero Q, Bendahl PO, Jirstrom K, Ryden L, Loman N, Uhlen M, Johannesson H, Rose C, Grabau D, et al. 2013 Targeting HMG-CoA reductase with statins in a window-of-opportunity breast cancer trial. Breast Cancer Research and Treatment 138 499-508. (https://doi.org/10.1007/s10549-013-2473-6)

Cancer Genome Atlas Research Network, Bell D, Berchuck A, Birrer M, Chien J, Cramer DW, Dao F, Dhir R, DiSaia P, Gabra H, et al. 2011 Integrated genomic analyses of ovarian carcinoma. Nature $\mathbf{4 7 4}$ 609-615. (https://doi.org/10.1038/nature10166)

Castells M, Thibault B, Delord JP \& Couderc B 2012 Implication of tumor microenvironment in chemoresistance: tumor-associated stromal cells protect tumor cells from cell death. International Journal of Molecular Sciences 13 9545-9571. (https://doi.org/10.3390/ ijms13089545)

Centers for Disease Control and Prevention (CDC) 2010 Prevalence of abnormal lipid levels among youths - United States 1999-2006. Morbidity and Mortality Weekly Report 59 29-33.

Collaborative Group on Epidemiological Studies of Ovarian Cancer 2012 Ovarian cancer and body size: individual participant meta-analysis including 25,157 women with ovarian cancer from 47 epidemiological studies. PLoS Medicine 9 e1001200. (https://doi. org/10.1371/journal.pmed.1001200)

DuSell CD, Umetani M, Shaul PW, Mangelsdorf DJ \& McDonnell DP 2008 27-Hydroxycholesterol is an endogenous selective estrogen receptor modulator. Molecular Endocrinology 22 65-77. (https://doi. org/10.1210/me.2007-0383)

DuSell CD, Nelson ER, Wang X, Abdo J, Modder UI, Umetani M, GestyPalmer D, Javitt NB, Khosla S \& McDonnell DP 2010 The endogenous selective estrogen receptor modulator 27-hydroxycholesterol is a negative regulator of bone homeostasis. Endocrinology $1513675-$ 3685. (https://doi.org/10.1210/en.2010-0080)

Eckert MA, Pan S, Hernandez KM, Loth RM, Andrade J, Volchenboum SL, Faber P, Montag A, Lastra R, Peter ME, et al. 2016 Genomics of ovarian cancer progression reveals diverse metastatic trajectories including intraepithelial metastasis to the Fallopian tube. Cancer Discovery 6 1342-1351. (https://doi.org/10.1158/2159-8290. CD-16-0607)

Eddie SL, Quartuccio SM, Oh E, Moyle-Heyrman G, Lantvit DD, Wei JJ, Vanderhyden BC \& Burdette JE 2015 Tumorigenesis and peritoneal colonization from fallopian tube epithelium. Oncotarget 6 20500-20512. (https://doi.org/10.18632/oncotarget.3985)

Elmore RG, Ioffe Y, Scoles DR, Karlan BY \& Li AJ 2008 Impact of statin therapy on survival in epithelial ovarian cancer. Gynecologic Oncology 111 102-105. (https://doi.org/10.1016/j.ygyno.2008.06.007)

Ferno J, Raeder MB, Vik-Mo AO, Skrede S, Glambek M, Tronstad KJ, Breilid H, Lovlie R, Berge RK, Stansberg C, et al. 2005 Antipsychotic drugs activate SREBP-regulated expression of lipid biosynthetic genes in cultured human glioma cells: a novel mechanism of action? Pharmacogenomics Journal 5 298-304. (https://doi.org/10.1038/sj. tpj.6500323)

Fialova A, Partlova S, Sojka L, Hromadkova H, Brtnicky T, Fucikova J, Kocian P, Rob L, Bartunkova J \& Spisek R 2013 Dynamics of T-cell infiltration during the course of ovarian cancer: the gradual shift from a Th17 effector cell response to a predominant infiltration by regulatory T-cells. International Journal of Cancer 132 1070-1079. (https://doi.org/10.1002/ijc.27759)

Gaillard SL, Secord AA \& Monk B 2016 The role of immune checkpoint inhibition in the treatment of ovarian cancer. Gynecologic Oncology Research and Practice 3 11. (https://doi.org/10.1186/s40661-016-0033-6)

Ganzfried BF, Riester M, Haibe-Kains B, Risch T, Tyekucheva S, Jazic I, Wang XV, Ahmadifar M, Birrer MJ, Parmigiani G, et al. 2013 curatedOvarianData: clinically annotated data for the ovarian cancer transcriptome. Database $\mathbf{2 0 1 3}$ bat013.

Gostynski M, Gutzwiller F, Kuulasmaa K, Doring A, Ferrario M, Grafnetter D, Pajak A \& Project WM 2004 Analysis of the relationship between total cholesterol, age, body mass index among males and females in the WHO MONICA Project. International Journal of Obesity and Related Metabolic Disorders 28 1082-1090. (https://doi.org/10.1038/sj.ijo.0802714)

Gyorffy B, Lanczky A, Eklund AC, Denkert C, Budczies J, Li Q \& Szallasi Z 2010 An online survival analysis tool to rapidly assess the effect of 22,277 genes on breast cancer prognosis using microarray data of 1,809 patients. Breast Cancer Research and Treatment 123 725-731. (https://doi.org/10.1007/s10549-009-0674-9)

Gyorffy B, Lanczky A \& Szallasi Z 2012 Implementing an online tool for genome-wide validation of survival-associated biomarkers in ovariancancer using microarray data from 1287 patients. Endocrine-Related Cancer 19 197-208. (https://doi.org/10.1530/ERC-11-0329)

Habis M, Wroblewski K, Bradaric M, Ismail N, Yamada SD, Litchfield L, Lengyel E \& Romero IL 2014 Statin therapy is associated with improved survival in patients with non-serous-papillary epithelial ovarian cancer: a retrospective cohort analysis. PLOS ONE 9 e104521. (https://doi.org/10.1371/journal.pone.0104521)

Haibe-Kains B, Schroeder M, Bontempi G, Sotiriou C \& Quackenbush J 2012 Genefu: relevant functions for gene expression analysis, especially in breast cancer. $R$ package version 1.8.0.

Hamanishi J, Mandai M \& Konishi I 2016 Immune checkpoint inhibition in ovarian cancer. International Immunology 28 339-348. (https://doi.org/10.1093/intimm/dxw020)

He S \& Nelson ER 2017 27-Hydroxycholesterol, an endogenous selective estrogen receptor modulator. Maturitas 104 29-35. (https://doi. org/10.1016/j.maturitas.2017.07.014)

Hogdall EV, Christensen L, Hogdall CK, Blaakaer J, Gayther S, Jacobs IJ, Christensen IJ \& Kjaer SK 2007 Prognostic value of estrogen receptor and progesterone receptor tumor expression in Danish ovarian cancer patients: from the 'MALOVA' ovarian cancer study. Oncology Reports 18 1051-1059.

Karuna R, Holleboom AG, Motazacker MM, Kuivenhoven JA, FrikkeSchmidt R, Tybjaerg-Hansen A, Georgopoulos S, van Eck M, van Berkel TJ, von Eckardstein A, et al. 2011 Plasma levels of 27-hydroxycholesterol in humans and mice with monogenic disturbances of high density lipoprotein metabolism. Atherosclerosis 214 448-455. (https://doi.org/10.1016/j.atherosclerosis.2010.10.042)

Kleffel S, Posch C, Barthel SR, Mueller H, Schlapbach C, Guenova E, Elco CP, Lee N, Juneja VR, Zhan Q, et al. 2015 Melanoma cell- (c) 2019 Society for Endocrinology Published by Bioscientifica Ltd. Printed in Great Britain 
intrinsic PD-1 receptor functions promote tumor growth. Cell 162 1242-1256. (https://doi.org/10.1016/j.cell.2015.08.052)

Kong YY, Fuchsberger M, Xiang SD, Apostolopoulos V \& Plebanski M 2013 Myeloid derived suppressor cells and their role in diseases. Current Medicinal Chemistry 20 1437-1444. (https://doi.org/10.2174/0 929867311320110006)

Kryczek I, Zou L, Rodriguez P, Zhu G, Wei S, Mottram P, Brumlik M, Cheng P, Curiel T, Myers L, et al. 2006 B7-H4 expression identifies a novel suppressive macrophage population in human ovarian carcinoma. Journal of Experimental Medicine 203 871-881. (https:// doi.org/10.1084/jem.20050930)

Kryczek I, Wei S, Zhu G, Myers L, Mottram P, Cheng P, Chen L, Coukos G \& Zou W 2007 Relationship between B7-H4, regulatory T cells, and patient outcome in human ovarian carcinoma. Cancer Research $\mathbf{6 7}$ 8900-8905. (https://doi.org/10.1158/0008-5472.CAN-07-1866)

Labidi-Galy SI, Papp E, Hallberg D, Niknafs N, Adleff V, Noe M, Bhattacharya R, Novak M, Jones S, Phallen J, et al. 2017 High grade serous ovarian carcinomas originate in the fallopian tube. Nature Communications 8 1093. (https://doi.org/10.1038/s41467-017-00962-1)

Lau J, Cheung J, Navarro A, Lianoglou S, Haley B, Totpal K, Sanders L, Koeppen H, Caplazi P, McBride J, et al. 2017 Tumour and host cell PD-L1 is required to mediate suppression of anti-tumour immunity in mice. Nature Communications 8 14572. (https://doi.org/10.1038/ ncomms14572)

Lavie O, Pinchev M, Rennert HS, Segev Y \& Rennert G 2013 The effect of statins on risk and survival of gynecological malignancies. Gynecologic Oncology 130 615-619. (https://doi.org/10.1016/j. ygyno.2013.05.025)

Lee JH, Gong H, Khadem S, Lu Y, Gao X, Li S, Zhang J \& Xie W 2008 Androgen deprivation by activating the liver $\mathrm{X}$ receptor. Endocrinology 149 3778-3788. (https://doi.org/10.1210/en. 2007-1605)

Li AJ, Elmore RG, Chen IY \& Karlan BY 2010 Serum low-density lipoprotein levels correlate with survival in advanced stage epithelial ovarian cancers. Gynecologic Oncology 116 78-81. (https://doi. org/10.1016/j.ygyno.2009.09.027)

Lindemann K, Gibbs E, Avall-Lundqvist E, dePont Christensen R, Woie K, Kalling M, Auranen A, Grenman S, Hoegberg T, Rosenberg P, et al. 2017 Chemotherapy vs tamoxifen in platinum-resistant ovarian cancer: a phase III, randomised, multicentre trial (Ovaresist). British Journal of Cancer 116 455-463. (https://doi.org/10.1038/ bjc.2016.435)

Lyons MA \& Brown AJ 2001 Metabolism of an oxysterol, 7-ketocholesterol, by sterol 27-hydroxylase in HepG2 cells. Lipids 36 701-711. (https://doi.org/10.1007/s11745-001-0775-8)

Meyn A \& Lim B 2017 A paradigm shift in the origin of ovarian cancer: the ovary is no longer to blame. BJOG 124 859. (https://doi. org/10.1111/1471-0528.14609)

Milne K, Alexander C, Webb JR, Sun W, Dillon K, Kalloger SE, Gilks CB, Clarke B, Kobel M \& Nelson BH 2012 Absolute lymphocyte count is associated with survival in ovarian cancer independent of tumorinfiltrating lymphocytes. Journal of Translational Medicine 1033. (https://doi.org/10.1186/1479-5876-10-33)

Must A, Spadano J, Coakley EH, Field AE, Colditz G \& Dietz WH 1999 The disease burden associated with overweight and obesity. JAMA 282 1523-1529. (https://doi.org/10.1001/jama.282.16.1523)

Nagle CM, Dixon SC, Jensen A, Kjaer SK, Modugno F, deFazio A, Fereday S, Hung J, Johnatty SE, Australian Ovarian Cancer Study Group, , et al. 2015 Obesity and survival among women with ovarian cancer: results from the Ovarian Cancer Association Consortium. British Journal of Cancer 113 817-826. (https://doi. org/10.1038/bjc.2015.245)

Nelson ER 2018 The significance of cholesterol and its metabolite, 27-hydroxycholesterol in breast cancer. Molecular and Cellular Endocrinology 466 73-80. (https://doi.org/10.1016/j. mce.2017.09.021)
Nelson ER, DuSell CD, Wang X, Howe MK, Evans G, Michalek RD, Umetani M, Rathmell JC, Khosla S, Gesty-Palmer D, et al. 2011 The oxysterol, 27-hydroxycholesterol, links cholesterol metabolism to bone homeostasis through its actions on the estrogen and liver X receptors. Endocrinology 152 4691-4705. (https://doi. org/10.1210/en.2011-1298)

Nelson ER, Wardell SE, Jasper JS, Park S, Suchindran S, Howe MK, Carver NJ, Pillai RV, Sullivan PM, Sondhi V, et al. 2013 27-Hydroxycholesterol links hypercholesterolemia and breast cancer pathophysiology. Science 342 1094-1098. (https://doi.org/10.1126/ science.1241908)

Nguyen-Vu T, Vedin LL, Liu K, Jonsson P, Lin JZ, Candelaria NR, Candelaria LP, Addanki S, Williams C, Gustafsson JÅ, et al. 2013 Liver $\mathrm{X}$ receptor ligands disrupt breast cancer cell proliferation through an E2F-mediated mechanism. Breast Cancer Research 15 R51. (https://doi.org/10.1186/bcr3443)

Norquist BM, Harrell MI, Brady MF, Walsh T, Lee MK, Gulsuner S, Bernards SS, Casadei S, Yi Q, Burger RA, et al. 2016 Inherited mutations in women With ovarian carcinoma. JAMA Oncology 2 482-490. (https://doi.org/10.1001/jamaoncol.2015.5495)

Patch AM, Christie EL, Etemadmoghadam D, Garsed DW, George J, Fereday S, Nones K, Cowin P, Alsop K, Bailey PJ, et al. 2015 Wholegenome characterization of chemoresistant ovarian cancer. Nature 521 489-494. (https://doi.org/10.1038/nature14410)

Pencheva N, Buss CG, Posada J, Merghoub T \& Tavazoie SF 2014 Broadspectrum therapeutic suppression of metastatic melanoma through nuclear hormone receptor activation. Cell 156 986-1001. (https:// doi.org/10.1016/j.cell.2014.01.038)

Pommier AJ, Alves G, Viennois E, Bernard S, Communal Y, Sion B, Marceau G, Damon C, Mouzat K, Caira F, et al. 2010 Liver X receptor activation downregulates AKT survival signaling in lipid rafts and induces apoptosis of prostate cancer cells. Oncogene 29 2712-2723. (https://doi.org/10.1038/onc.2010.30)

Pradeep S, Kim SW, Wu SY, Nishimura M, Chaluvally-Raghavan P, Miyake T, Pecot CV, Kim SJ, Choi HJ, Bischoff FZ, et al. 2014 Hematogenous metastasis of ovarian cancer: rethinking mode of spread. Cancer Cell 26 77-91. (https://doi.org/10.1016/j.ccr.2014.05.002)

Robinson-Smith TM, Isaacsohn I, Mercer CA, Zhou M, Van Rooijen N, Husseinzadeh N, McFarland-Mancini MM \& Drew AF 2007 Macrophages mediate inflammation-enhanced metastasis of ovarian tumors in mice. Cancer Research 67 5708-5716. (https://doi. org/10.1158/0008-5472.CAN-06-4375)

Scoles DR, Xu X, Wang H, Tran H, Taylor-Harding B, Li A \& Karlan BY 2010 Liver $X$ receptor agonist inhibits proliferation of ovarian carcinoma cells stimulated by oxidized low density lipoprotein. Gynecologic Oncology 116 109-116. (https://doi.org/10.1016/j. ygyno.2009.09.034)

Sica A, Larghi P, Mancino A, Rubino L, Porta C, Totaro MG, Rimoldi M, Biswas SK, Allavena P \& Mantovani A 2008 Macrophage polarization in tumour progression. Seminars in Cancer Biology 18 349-355. (https://doi.org/10.1016/j.semcancer.2008.03.004)

Svoronos N, Perales-Puchalt A, Allegrezza MJ, Rutkowski MR, Payne KK, Tesone AJ, Nguyen JM, Curiel TJ, Cadungog MG, Singhal S, et al. 2017 Tumor cell-independent estrogen signaling drives disease progression through mobilization of myeloid-derived suppressor cells. Cancer Discovery 7 72-85. (https://doi.org/10.1158/2159-8290.CD-16-0502)

Szanto A, Benko S, Szatmari I, Balint BL, Furtos I, Ruhl R, Molnar S, Csiba L, Garuti R, Calandra S, et al. 2004 Transcriptional regulation of human CYP27 integrates retinoid, peroxisome proliferatoractivated receptor, and liver $\mathrm{X}$ receptor signaling in macrophages. Molecular and Cellular Biology 24 8154-8166. (https://doi. org/10.1128/MCB.24.18.8154-8166.2004)

Tang JJ, Li JG, Qi W, Qiu WW, Li PS, Li BL \& Song BL 2011 Inhibition of SREBP by a small molecule, betulin, improves hyperlipidemia and insulin resistance and reduces atherosclerotic plaques. Cell Metabolism 13 44-56. (https://doi.org/10.1016/j.cmet.2010.12.004) https://erc.bioscientifica.com https://doi.org/10.1530/ERC-18-0572
C) 2019 Society for Endocrinology Published by Bioscientifica Ltd. Printed in Great Britain 
Tavazoie MF, Pollack I, Tanqueco R, Ostendorf BN, Reis BS,

Gonsalves FC, Kurth I, Andreu-Agullo C, Derbyshire ML, Posada J, et al. $2018 \mathrm{LXR} / \mathrm{ApoE}$ activation restricts innate immune suppression in cancer. Cellule 172 825.e818-840.e818.

Umetani M, Domoto H, Gormley AK, Yuhanna IS, Cummins CL, Javitt NB, Korach KS, Shaul PW \& Mangelsdorf DJ 2007 27-Hydroxycholesterol is an endogenous SERM that inhibits the cardiovascular effects of estrogen. Nature Medicine 13 1185-1192. (https://doi.org/10.1038/nm1641)

van Baal JOAM, van Noorden CJF, Nieuwland R, Van de Vijver KK, Sturk A, van Driel WJ, Kenter GG \& Lok CAR 2018 Development of peritoneal carcinomatosis in epithelial ovarian cancer: a review. Journal of Histochemistry and Cytochemistry 66 67-83. (https://doi. org/10.1369/0022155417742897)

Vedin LL, Lewandowski SA, Parini P, Gustafsson JA \& Steffensen KR 2009 The oxysterol receptor LXR inhibits proliferation of human breast cancer cells. Carcinogenesis 30 575-579. (https://doi. org/10.1093/carcin/bgp029)
Voutsadakis IA 2016 Immune blockade inhibition in breast cancer. Anticancer Research 36 5607-5622. (https://doi.org/10.21873/ anticanres.11145)

Wu Q, Ishikawa T, Sirianni R, Tang H, McDonald JG, Yuhanna IS, Thompson B, Girard L, Mineo C, Brekken RA, et al. 2013

27-Hydroxycholesterol promotes cell-autonomous, ER-positive breast cancer growth. Cell Reports 5 637-645. (https://doi.org/10.1016/j. celrep.2013.10.006)

Yang SYC, Lheureux S, Karakasis K, Burnier JV, Bruce JP, Clouthier DL, Danesh A, Quevedo R, Dowar M, Hanna Y, et al. 2018 Landscape of genomic alterations in high-grade serous ovarian cancer from exceptional long- and short-term survivors. Genome Medicine 1081. (https://doi.org/10.1186/s13073-018-0590-x)

Yu YR, O'Koren EG, Hotten DF, Kan MJ, Kopin D, Nelson ER, Que L \& Gunn MD 2016 A protocol for the comprehensive flow cytometric analysis of immune cells in normal and inflamed murine nonlymphoid tissues. PLOS ONE 11 e0150606. (https://doi.org/10.1371/ journal.pone.0150606)

Received in final form 10 April 2019

Accepted 2 May 2019

Accepted Preprint published online 2 May 2019 (c) 2019 Society for Endocrinology Published by Bioscientifica Ltd. Printed in Great Britain 